\title{
THE SOCIAL ORGANIZATION OF AUTHENTICITY IN MEXICAN RESTAURANTS
}

A Dissertation
presented to
the Faculty of the Graduate School
at the University of Missouri-Columbia
In Partial Fulfillment
of the Requirements for the Degree
Doctor of Philosophy
by
STEPHEN R. CHRIST
Dr. Jaber F. Gubrium, Dissertation Supervisor
July, 2015


The undersigned, appointed by the dean of the Graduate School, have examined the dissertation entitled

“THE SOCIAL ORGANIZATION OF AUTHENTICITY IN MEXICAN RESTAURANTS"

Presented by Stephen R. Christ, A candidate for the degree of Doctor of Philosophy

And hereby certify that, in their opinion, it is worthy of acceptance.

Professor Jaber F. Gubrium

Professor Ibitola O. Pearce

Professor Wayne H. Brekhus

Professor Matt Foulkes 


\section{DEDICATION}

For all my friends working in restaurant kitchens who were kind enough to share their worlds with me. 


\section{ACKNOWLEDGEMENTS}

This dissertation is the end product of a long process of work. I would like to think that I graciously and personally thanked every individual who contributed in any form to my development as a scholar and a researcher over my years of undergraduate and graduate education. So as not to disrupt the traditional ritual of thanking, I will once again give thanks to everyone who encouraged, inspired, and quite honestly, terrified me along the way. Rituals such as these can become cliquey, especially if you are left of the list of those thanked. To avoid this, I first wish to issue a blanket thank you statement. If for whatever reason you do not find your name mentioned below in a formal thank you, please know that I am thankful for whatever kind deed, gesture, or act you did on my behalf. I must ask you for one more - please pardon my ignorance. Thank you.

Being thankful is always an exercise in honesty. Being honest with yourself and being honest with someone who had an influence on you. Even in a dissertation about "authenticity," the genuine character of a thank you may come into question. I truly respect and am gracious to the faculty and staff of the University of Missouri Sociology department. I would first like to thank Jay

Gubrium. Before I met Jay at MU, I read his book, "Living and Dying at Murray Manor" as an undergrad, so much like his reputation, his influence precedes him as well. My first interaction with Jay was in a graduate seminar. On the first day before he arrived in class, my colleagues in the course whispered nervously stories of how grueling of an instructor and intimidating/confrontational of a scholar Jay was. To say the least, I was panic-stricken, but once Jay arrived and charismatically introduced himself and his research interests, I knew I wanted to work with him. Over the years, Jay has been a consistent and compassionate encouraging force in my life. He has built within me a sense of confidence that I 
am capable of being a researcher. I am forever indebted to Jay for providing me with his wisdom, encouragement, and friendship. Thank you, Jay.

I would also like to thank Tola Pearce for being the single most intimidating person I have ever interacted with. Her cool confidence and no-nonsense approach to research and social justice challenged me to be a better student, researcher, and advocate of human rights. I thank Tola for inviting me to her graduate seminar to present my research, get feedback, and to have great discussions on culture, authenticity, and globalization. Moments like these were truly invaluable to my development as a scholar. Thank you, Tola.

I would also like to thank Wayne Brekhus for showing me that producing top-notch research and being an academic superstar does not necessarily mean that you no longer can put on a pair of pink tube socks and have fun. Much of what I learned about being a teacher/scholar comes from Wayne. Having taken several of his seminars over the years, I have tried to mirror his fun, engaging, and ever critical approach to research and teaching. I hope that as I enter academia that I can retain half of the charisma and passion for teaching which Wayne has. Thank you, Wayne.

I would also like to thank Matt Foulkes. While I have not taken many classes with Matt, the material which I was to exposed to in his Migration/Immigration course remains fundamental to my current research emphasis on Mexican immigration and assimilation. It was actually his course which motivated me to shift my research emphasis from religion and rituals to contemporary immigration to new destinations. I am thankful to Matt for providing me with this inspiration. Thank you, Matt.

I would also like to thank my family. From my parents who worked tirelessly to give me the opportunity to get an education to my brother with whom 
I competed with in every aspect our lives, especially grades. I can't imagine having a better group of supporters/competitors. Thank you for pushing me to pursue my goals, bringing me back down to earth when I got a bit too arrogant, and for never being anything but the kindest people in my life. Thank you, Mom, Dad, and Brandon.

Last, but certainly not least, I would like to thank my wife, Marie. I credit Marie with getting me interested in studying social life. It was her long distance phone calls during our undergrad years when she would read her term papers out loud to me for proofreading purposes that I became interested in issues like inequalities. It was this exposure which drew me away from chemistry and towards immigration. Aside from being an academic role model for me, Marie makes me happy —no small task in graduate school. I am forever indebted to her for being my rock, counselor, and biggest fan. Thank you, Marie. 


\section{TABLE OF CONTENTS}

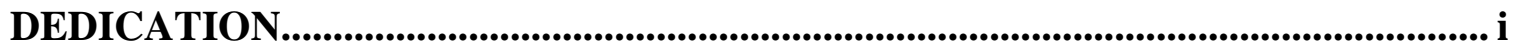

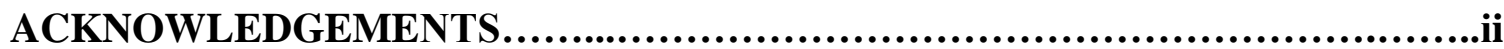

TABLE OF CONTENTS ....................................................................................................... v

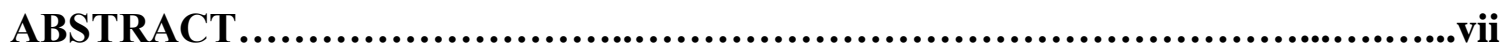

CHAPTER ONE: INTRODUCTION ................................................................... 1

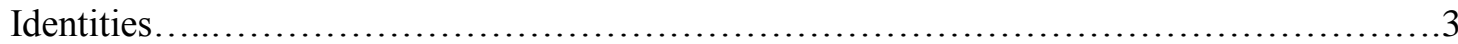

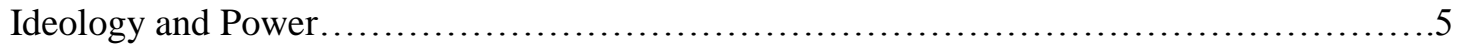

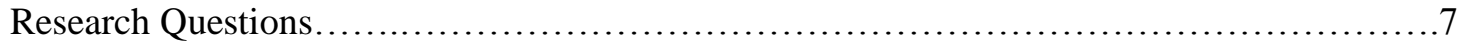

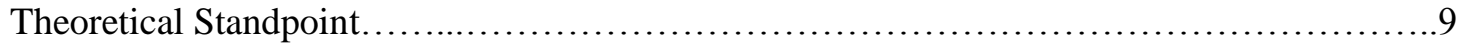

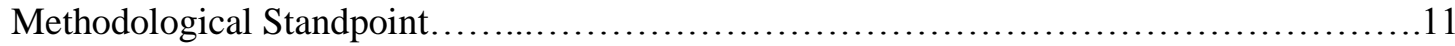

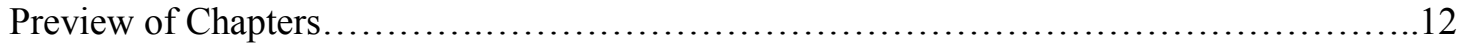

CHAPTER TWO: ORGANIZATIONAL RHYTHMS ................................................ 15

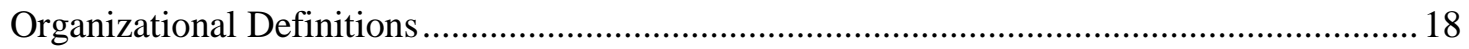

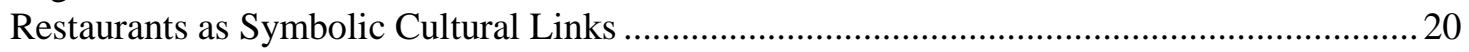

Marketing Authenticity and Culture …………………….............................................22

The Social Organization of Authenticity ...................................................... 23

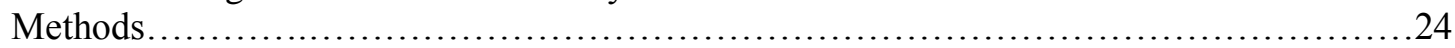

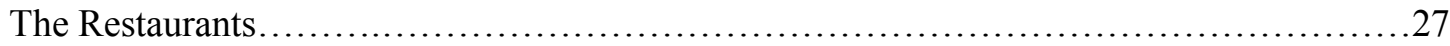

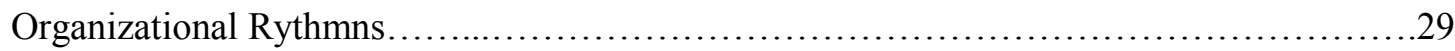

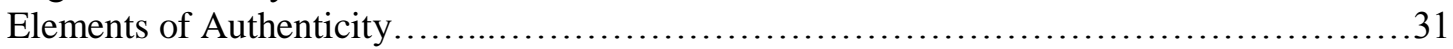

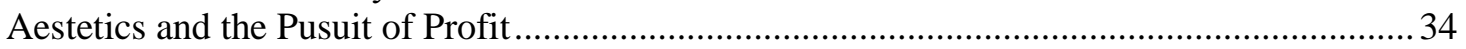

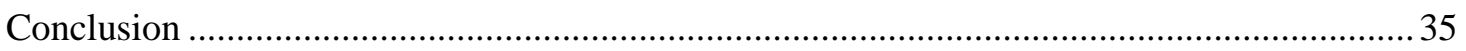

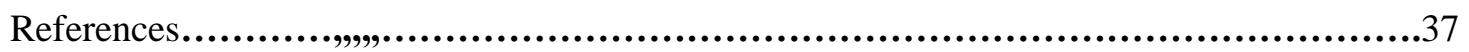

CHAPTER THREE: MASCULUNITY IN MEXICAN RESTAURANT WORK... 42

Migrant Labor in a Globalized World.............................................................................4 43

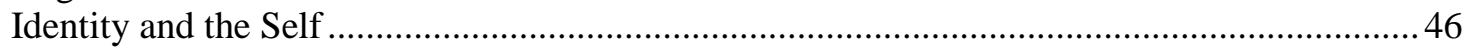

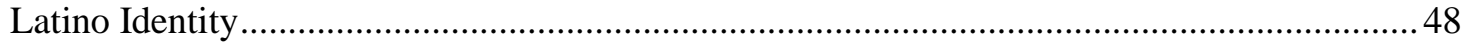

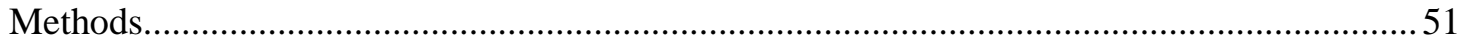

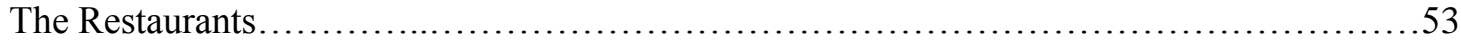

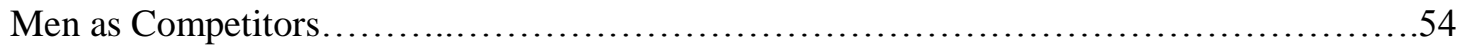

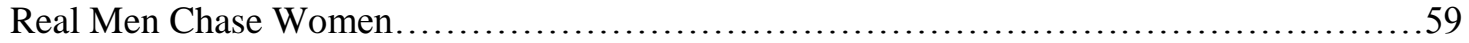

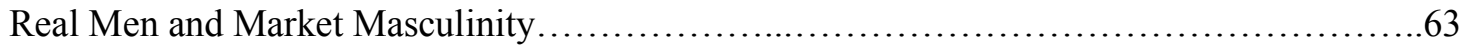

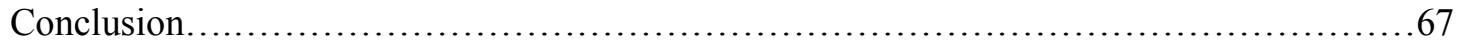

References............................................................................................................................69

CHAPTER FOUR: COOKING WHILE BROWN: .............................................. 72

A Critical Race Theory Approach....................................................... 74

Ethnic Restaurants in the United States............................................... 76

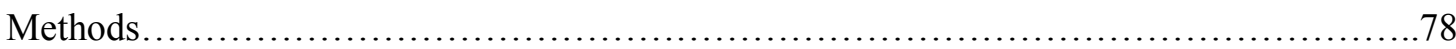

Shifting Dimensions of Power and Discrimination................................... 82

Effect of Ethnic Status on Health Inspection Scores......................................... 89

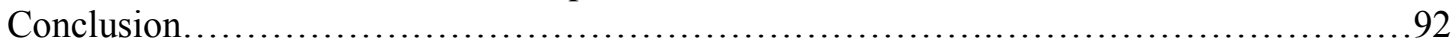

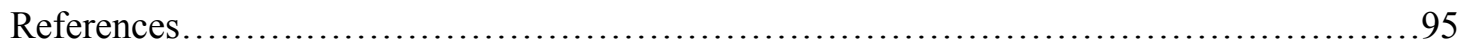


CHAPTER FIVE: CONCLUSION AND DISCUSSION ............................................... 98

The Rhythms of Mexican Restaurant Work ........................................... 100

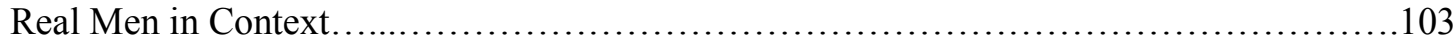

Perceptions and Realities of Discrimination in Ethnic Restaurants.......................106

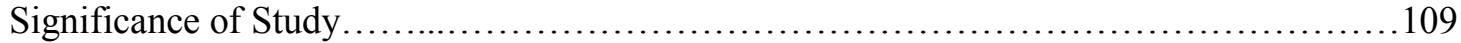

Future Research..................................................................... 110

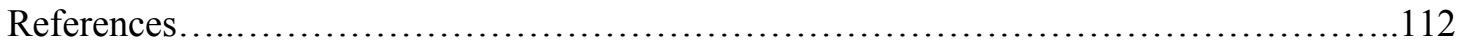

APPENDIX A: INTERVIEW PROTOCOL.......................................115

APPENDIX B: LETTER OF INFORMED CONSENT ..............................118

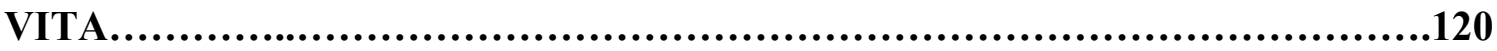




\title{
"THE SOCIAL ORGANIZATION OF AUTHENTICITY IN MEXICAN RESTAURANTS"
}

\author{
Stephen R. Christ \\ Dr. Jay Gubrium, Dissertation Supervisor
}

\begin{abstract}
This dissertation analyzes the social worlds of the Mexican restaurant industry. First, the topic of organizational constructions and presentations of authenticity is investigated. In examining the relation between discourses of business (profit) and aesthetics (authenticity) in Mexican restaurant contexts in which authenticity is a major theme, this study demonstrates the processes of negotiation and policing which form the "authentic" experience for patrons of restaurants. By analyzing food, from its production to its consumption in Mexican restaurant organizational contexts, this dissertation investigates the dialectic relationship linking explicitly ethnic foods and an American consumer base which desires a real, genuine, or "authentic" meal.

The second major theme explored in this dissertation is the subjective dimension of authenticity among Mexican immigrant men working in the Mexican restaurant industry. In many restaurants across the United States, Mexican immigrant labor satisfies the high demand for low skilled service industry workers. The research explores the gendered niche of male Mexican restaurant cooks and servers. Traditionally marked as women's work, restaurant food preparation and serving is almost exclusively a male dominated niche of the labor force. Based on data gathered in the field, this project introduces the concept of gender posturing and homosocial behaviors as a means of developing a
\end{abstract}


pragmatic understanding of the many ways male restaurant workers define, perform, negotiate, and police the boundaries of acceptable forms of masculinity while simultaneously performing traditional feminine work in a socially constructed workplace in which masculinity is of premium importance

The third major theme of this project blends discussions of organizational and subjective dimensions of authenticity as it explores the basis and negative impacts of stereotypes on ethnic restaurant profitability. An examination of the institutional bias ethnic restaurant owners and workers perceive and experience during regular county health inspections demonstrates the influence of public discourse on the marking of ethnic restaurants. Based on data suggesting most ethnic restaurants are commonly perceived as "dirty" or "unclean" by predominantly White community members and health inspectors, this project concludes that as a result of these perceptions, ethnic restaurants are more likely to receive health code violations than generic "American" restaurants. In order to accomplish a comprehensive investigation of the matter, this study incorporates quantitative analysis of public health violation data for Ten Missouri counties, as well as ethnographic data from participant observations in ethnic restaurants. Special emphasis is placed on the structural construction of racially and ethnically themed restaurants as being dangerous and dirty, and the economic consequences for restaurant owners who must deal with the legal and economic issues resulting from their bias health inspection results. 


\section{CHAPTER 1}

\section{INTRODUCTION}

"If you wish to make an apple pie from scratch, you must first invent the universe." - Carl Sagan, Cosmos

Mexican food is a global phenomenon. But what exactly is Mexican food? While a plethora of ambiguity exists as to what exactly constitutes "authentic" Mexican food, the popularity of Mexican restaurants is increasing on a global level (Abarca 2004; Gaytán 2008). Along with Chinese and Italian, Mexican food is among the top three ethnic cuisines favored by restaurant patrons across the United States (Long 2013). What makes such a statistic so significant is the fact that the popularity of Mexican food is a recent phenomenon. As recent as the 1960's most Americans outside of the Southwestern Borderlands did not have access to or knowledge of Mexican foods, such as tacos, enchiladas, or mole (Pilcher 2014). Now, Mexican restaurants thrive in locations ranging from Barrow, Alaska to Sydney, Australia; and from Addis Ababa, Ethiopia to Ulan Bator, Mongolia (Pilcher 2012).

Additionally, advances in the technologies of food preservation and packaging have made it possible to eat Mexican food virtually anywhere a Mexican restaurant is not located, on Earth or in space. NASA has recently incorporated Mexican tortillas in food rations sent to astronauts on the International Space Station. With such a tremendous presence across the United States and the globe, one might easily assume that there is a tremendous variety in the forms and flavors represented as Mexican food. As a manifestation of modern globalization, Mexican foods and foodways have been commodifed and shared across cultures and national borders, in many cases without the work of the people they belong to (Mulholland 2007; Gaytán 2008). The question, then, 
of what people are eating and how that connects to ideas of Mexican culture, food, and community is of central interest to this project. At the core of this dissertation is an interrogation of the ambiguity of "authenticity" and food traditions associated with the modern Mexican restaurant industry in the United States. As in, in such an era of globalization and the exchange of goods, peoples, and cultures, what does authenticity mean? Who has the power to define or to influence definitions of authenticity?

This dissertation is an exploration of the organizational and subjective identity work which produces the social universe of Mexican meaning systems, communities, and food. The original meaning of the famous phrase quoted from Carl Sagan at the start, carried with it the meaning that all matter found on Earth was not necessarily unique to the planet or the product of one single act. Rather, a universe of materials and forces have produced and are continuously reproducing the materials used for an apple pie. This theoretical conceptualization has tremendous transferability and applicability to the social worlds we create in our everyday lives. On a basic level, and to continue the metaphor, in order for a chef to make an apple pie, they must first have the necessary ingredients: apples, flour, sugar, etc. These ingredients, however, do not appear out of thin air. Rather, the apples were most likely picked by migrant laborers from Latin America, the sugar was most likely refined in a large conglomerate's food processing facility, and the cook was most likely taught to prepare the meal by a family member, instructor at school, or in modern times, through a YouTube video found on the internet.

Perhaps most importantly to this research project is the development of the recipe for the apple pie. In many ways, recipes represent the "true" or "real" way to make the specific dish. That is to say, people with authority have established the rules for making 
"authentic" apple pie. This dissertation seeks to explore the social universe of Mexican food production in order to understand how notions of authenticity are generated and maintained in restaurants across social, political, and geographic contexts.

Over the last twenty years there has been quite a bit written about immigration to new destinations in the Midwest, social, political, and economic impacts of immigrants in these new contexts, and ethnic group identities which either dissolve through assimilation or crystalize as a result of institutional barriers to social integration. While these areas represent important dimensions of social life, lacking from the the literature on ethnic group identity is research on the efforts of immigrant entrepeneurs to commodify their culture and work to maintain ideologies of authenticity.

\section{Identities}

In order to produce any relevant contribution to social theory, a researcher must not overlook the complicated processes which go into the construction of realities and identities across a range of dimensions (Smith 2005; Collins 1990; Crenshaw 1989). Indeed, discovering the everyday experiences of people, and their significances holds tremendous value in understanding the constant interaction of structures and agency (Giddens 1990). This understanding better prepares a social scientist to analyze everyday activities and to recognize the constellation of meanings that serve as the basis for actions (Bourgois and Schonberg 2007; Gubrium 1999). A researcher must recognize that reality is a fluid construction based in specific contexts in which many individuals may possess a stake in their development and perpetuation. Applying these tenets, recent developments in the study of culture have expanded once monolithic conceptions of cultures and groups and begun to appreciate the intersectionalities of social actors. Socially constructed 
categories such as national identity, race, ethnicity, and gender typify boundaries between and within groups. The present study will build on this discussion of contested cultural meanings by examining the shared motives and behaviors of individuals in the Mexican restaurant industry policing the boundaries of authenticity.

Interpretations of Culture-An Intersectional Approach

Major critiques of contemporary social theory and cultural studies cite a lack of applicability to marginalized individuals in society (Smith 2005; Crenshaw 1991;

Steedman 1987). That is to say mainstream social theory denies certain individuals in society, "a particular story, a personal history, except when that story illustrates a general thesis" (Steedman 1987:10). This failure to recognize that the participants of a study, as well as all members of society, possess a range of diverse thoughts, personalities, and experiences limits the validity of social research and is an injustice to further marked and marginalized populations. Intersectional theorists seek to move beyond simplistic and stereotypical representations. Rather than examine one variable at a time (nationality, race, social class, gender, etc.), intersectionality theory is based on the notion that variables such as these function together and are constantly overlapping producing interlocking systems of social influence (Collins 1990; Said 1979). These systems of control and oppression are created by a long history of unequal distribution of economic and legal power, and control (Pharr 1997; Collins 1990).

Lamont (2000) provides an exemplary case of how individuals in society sharing seemingly parallel characteristics vary dramatically in their personal values, politics, and actions. In a study of working class men she found that a strong work ethic, highly regulated self-discipline and a strong narrative of individualism were key aspects of 
morality among white American workers. Black workers were fairly different in their construction of values. Black American workers were centered on the notions of solidarity and family. These workers were primarily concerned with caring for their community, being generous and forming close relationships. Lamont attributes this sense of mutual obligation to the socio-historical and economic location of African Americans in society.

As a result of a long history of discrimination and prejudice, the Black workers in her study often lived in crime prone areas. The need for solidarity, thus, was ever present in order to protect the community. In addition to the variance in values and kinship responsibilities, one can easily assume that many other differences exist between and within these groups. That is to say, variables other than social class have a determining role on the experiences and agency of individuals in seemingly monolithic groups. Indeed, an emerging body of cultural studies have shown how individuals within seemingly monolithic groups such as people without homes (Bourgois and Schonberg 2007), mixed martial arts fighters (Abramson and Modlewski 2010), and exotic dancers (Ronai 1992) vary wildly based on their social class, gender, race, ethnicity and a slew of additional dimensions. Discounting these intersections only serves to reinforce negative stereotypes which inform mainstream ideologies of marginalized groups (Bourgois and Sconberg 2007).

\section{Ideology and Power}

Stuart Hall (1986) defines ideology as "the mental frameworks --the languages, the concepts, categories, imagery of thought, and systems of representation --which different classes and social groups deploy in order to make sense of, define, figure out and render 
intelligible the way society works" (26). Hegemonic ideologies are constructed through coercion as well as constant repetitive acts of persuasion. In the case of the dominant hegemonic ideology of immigration in the United States, we see that popular political figures and campaigns direct how Americans construct their citizenship and how they construct their understandings of immigrants. In the U.S., the term immigrant is almost always articulated to mean "Mexican." This is problematic not only because it assumes all immigrants to the U.S. are Mexican, but also because it carries with it a negative connotation which ignores the "hegemonic power relations that intertwine privileges of class with those of race, ethnicity, gender and nationality" (Apostolidis 2005).

This ideology dominates our perceptions and reinforces the notion we are led to believe; that immigrants are all the same (lazy, violent drains on the economy), and that immigration has adverse effects on our economies and society. Indeed, we must recognize that all Latino/a, immigrants, and even White Americans are not the same. Members of these classifications experience social life in significantly different ways based on their social class, physical appearance, geographic location, political ideology, etc. Ann Stoler (2002) analyzes imperialism, colonialism, and the politics that create and maintain these uneven experiences and power relations. She challenges traditional views of cultural and structural dominance by highlighting the complexity of social life. Stoler advocates for an appreciation of the complex and fluid nature of social life and politics. She suggests in order to properly study and interpret the social realities of colonial life, we must remain open minded to the many fluid social categories which contributed to its structure. In other words, we must move beyond simple explanations of complex matters and seek to unpack previously homogenized individuals, groups, and cultures. 


\section{Research Questions and Methodological Approach}

Building on this discussion, my dissertation explores the organizational and subjective identity work that occurs in Mexican restaurants in order to gain a richer understanding of how authenticity is conceptualized, interpreted, and marketed in a 21 st century globalized world. The central research question that this study aims to answer is, how do owners, servers, and ethnic patrons of Mexican restaurants construct, preserve, and police the boundaries of authenticity in their everyday interactions, their work, and their communities in the Midwest, Southwestern Borderland, and in Mexico.

This unique contribution to the literature on the construction and social organization of authenticity in Mexican restaurants was structured as an exploratory ethnographic multiple case study. An ethnographic multiple case study design was ideal for this research because of the necessity of context in the material covered and thus, ensured reflective descriptions of social contexts, interactions, and cultures of restaurants and those who worked and dined at them. Not bogged down in theory, ethnography can be described as an approach aimed at discovering the everyday experiences of people. Jay Gubrium (2011) defines ethnographic fieldwork as being a research method which is "traditionally participatory and observational, but it also has been something elseconcerned with how people themselves account for experience" (6). Inherent to this analytical strategy is the belief that the researcher must acknowledge and value the everyday experiences of people. This understanding better prepares an ethnographic fieldworker to study everyday activities and to recognize the constellation of meanings that serve as the basis for how interactions and activities are constructed and reified. 
Culture and identity are complex multi-dimensional social constructions which continuously change. Studies of culture and identity range from emotion work (Simon et al 1992; Hochschild 1983; Gordon 1981), symbolic presentations of self (Min 2010; Jimenez 2009; Macias 2004; Waters 1990), interrogations of the gendered body (Lamont 2000; Banet-Weiser 1999; Gergen and Gergen 1993), and an ever growing plethora of emerging research on the social worlds we create. The catalysts for this change are the ongoing social interactions which social actors participate in in their everyday lives. Therefore, in order to understand culture and identity, a researcher must go to the people, interrogate their social interactions, and analyze the social structures in which they are embedded (Smith 2005).

Herbert Blumer (1986) and George Herbert Mead (1967) provide a good point of departure for a discussion of realizing the nature of culture of identity and methods for interrogating them. In Symbolic Interaction, Herbert Blumer proposes the notion that society functions as and through symbolic interaction. Implicit to this theoretical standpoint is the position that society is composed of individuals communicating through a wide array of gestures, symbols, and languages. It is the sum of all these interactions which creates society. In this sense, society is viewed as a social construction of independent social actors. It is important to note the fluid nature of these interactions. Indeed, the meanings attached to gestures, symbols and language have been continuously changing since their initial development, and with them, so too has changed society. Over time and through countless interactions, ideas such as democracy, Americanism, and even sociological theory have been constructed and maintained by society (Anderson 1991; Berger and Luckman 1967). This illustrates the need to view society through a 
symbolic interaction lens, with special attention on the root of all meaning - that of symbolic interactions between social actors. According to symbolic interactionists, in order to understand society, we must focus our scholarly attention on the micro-level interactions which when viewed in their totality, compose society. Symbolic Interaction-A Theoretical Standpoint

In order to think about society from the symbolic interactionist theoretical perspective, one must first understand the basic tenants of the standpoint. It was Mead (1967) who first asked the question of what holds human society together. Rather than base his ideas in essentialist or conflict perspectives, he assumed the theoretical standpoint that individuals in society align their actions in situations with the actions of other social actors present in a given context in continuous interpretive sequences. This pragmatic theoretical standpoint acknowledges a social actor's ability to unceasingly interpret the social world around them. This is to say that social actors do not simply react to an object or enter an interaction with a pre-developed meaning and response. Rather, the interpretive process begins when two social actors are aware that an interaction is occurring and is continuously being re-interpreted and developed. Indeed, it is only through social interactions that objects acquire meaning (Swidler 1986; Blumer 1986; Goffman1959).

Thus, to Mead, human consciousness cannot be alienated from action and interaction, but must be understood as a fundamental component of both. Indeed, in the theoretical framework, social actors are empowered in the sense that they are seen as active constructers of their selves, identities, and interpretations. They are not merely seen as passive sponges which absorb cultural norms and values from thin air, but rather 
as active social actors who define, interpret, and construct their actions, the actions of others, and shared meanings in society. It is out of these interactions that notions of shared symbols and meanings emerge and become the basis for future interactions and interpretations. Indeed, as Mead points out, "all organized society—even in its most complex and highly developed forms - is in a sense merely an extension and ramification of those simple and basic socio-psychological relations among its individual members...upon which it is founded" (Mead 1967: 229).

A major tenet of the symbolic interactionist theoretical perspective is the notion that individual actors possess the power to both create and change society through their interactions (Anderson 1991; Karp, et al 1993; Berger and Luckman 1967). Blumer accepted this theoretical perspective put forth by Mead, but had, in his view, a few particularities that advanced symbolic interactionism as a theory. To Blumer, society and social interactions were composed of unpredictable and constantly emerging social processes. In this sense, we are constantly creating and refining our selves, meanings, interpretations - and thus, society. We possess a situational self by which we interpret and are interpreted (Gubrium and Holstein 1999). We possess the agency and the ability to create this situational self in our interactions (Jimenez 2010; Hochschild 1983; Goffman 1959). Indeed, much like our situational self, society is viewed as an unfixed, fluid and continuously evolving social construction (Mead 1967).

Blumer's symbolic interactionist theoretical perspective may be illustrated with the example of a salad. The individual components of a salad (lettuce, tomato, cucumber, etc.) possess distinct meanings and are interpreted differently. Once they are blended together, they take on a new, uniform meaning. Nevertheless, while the individual pieces 
are still very much visible (there is no confusing the tomato from the cheddar cheese in salad), the individual components are viewed together in their totality as a whole - a salad. Society exists through an amassing of social interactions. Thus, in the theoretical understanding of society, one must not overlook the agency of individuals to create and maintain society as a whole. Once a researcher acknowledges symbolic interactions as the genesis of society, a methodological framework by which one can best gather data on social actors in society emerges.

\section{Symbolic Interaction - A Methodological Standpoint}

In his work, Herbert Blumer outlines a very clear methodology which he believes will properly capture the fluid intricacies of society. According to Blumer, "the task of the research scholar who is studying any sphere of social life is to ascertain what form of interaction is in play instead of imposing on that sphere some preset form of interaction" (Blumer 1986:54). Blumer viewed symbolic interaction not merely as a philosophical doctrine, but also as an essential perspective by which to "yield verifiable knowledge of human group life and human conduct" (Blumer 1986:21). In this sense, social scientific research needs to be based in inductive logic. That is to say that we should not approach a context of intellectual inquiry with any preconceived notions or theoretical frameworks which will frame our interpretations of the interactions within the context. In order to best interpret the empirical world, we must gather rigorous observations of verbal and non-verbal exchanges and interactions between social actors (Douglas et. al 1980; Geertz 1973). We must see the context which we are studying through the eyes and standpoints of the people in that specific context. 


\section{Preview of Chapters}

This dissertation will take the format of three publishable articles with an introduction and conclusion. The introduction here which presents the topics covered in the articles and to draw connections between different findings found throughout. The conclusion will serve as a comprehensive analysis of the findings of this dissertation research and to generate discussions of future research and theoretical development. This dissertation will examine authenticity on two levels: organizational and individual/subjective.

Chapter 2, the first article, explores organizational constructions and presentations of authenticity. It examines the relation between discourses of business (profit) and aesthetics (authenticity) in Mexican restaurant contexts in which authenticity is a major theme. By analyzing food, from its production to its consumption in Mexican restaurant organizational contexts, the article investigates the dialectic relationship linking explicitly ethnic foods and an American consumer base which desires a real, genuine, or "authentic" meal. The results of the article show that the tensions between differing perceptions of authentic Mexican food and restaurant foodways within the organizational setting of the restaurant must be carefully managed by restaurant staff in order to sufficiently meet the general public's perception of "authentic" Mexican food. This raised vigilance produces an organizational culture embedded in a joint practice of maintaining the illusion of authenticity to patrons.

Chapter 3, the second article, explores the subjective dimension of authenticity among Mexican immigrant men working in the Mexican restaurant industry. In many restaurants across the United States, Mexican immigrant labor satisfies the high demand 
for low skilled service industry workers. The article explores the gendered niche of male Mexican restaurant cooks and servers. Traditionally marked as women's work, restaurant food preparation and serving is almost exclusively a male dominated niche of the labor force. The article introduces the concept of gender posturing and homosocial behaviors as a means of developing a pragmatic understanding of the many ways male restaurant workers define, perform, negotiate, and police the boundaries of acceptable forms of masculinity while simultaneously performing traditional feminine work in a socially constructed workplace in which masculinity is of premium importance. In other words, how Mexican immigrants conceptualize and perform "authentic" manhood in their interactions at work at in their private lives.

Chapter, the third article, 4 blends discussions of organizational and subjective dimensions of authenticity as it explores the basis and negative impacts of stereotypes on ethnic restaurant profitability. Special emphasis is placed on ethnicized stereotypes of immigrants and how this discourse relates to public perceptions and patronage of Mexican restaurants. The article examines the institutional bias ethnic restaurant owners and workers perceive and experience during regular county health inspections. Since many ethnic restaurants in the Midwest are commonly perceived as "dirty" or "unclean" by predominantly White community members and health inspectors, this article concludes that as a result of these perceptions, ethnic restaurants are more likely to receive health code violations than generic "American" restaurants. In order to properly understand the relationship between public stereotypes of ethnic restaurants and bias in health code inspections of ethnic restaurants, the article incorporates quantitative analysis of public health violation data for Ten Missouri counties, as well as ethnographic data 
from participant observations in ethnic restaurants. Special emphasis is placed on the structural construction of racially and ethnically themed restaurants as being dangerous and dirty, and the economic consequences for restaurant owners who must deal with the legal and economic issues resulting from their bias health inspection results. 


\section{CHAPTER 2}

\section{AUTHENTICITY AND ORGANIZATIONAL RHYTHMS}

Abstract: This research examines the relation between discourses of business (profit) and aesthetics (authenticity) in Mexican restaurant contexts in which authenticity is a major theme. By analyzing food, from its production to its consumption in these organizational contexts, this research investigates the dialectic relationship linking explicitly ethnic foods and an American consumer base which desires a real, genuine, or "authentic" meal. Using participant observation, interviews with owners, workers, and patrons of Mexican restaurants and content analysis of online restaurant reviews, the results of this study show that the tensions between differing perceptions of authentic Mexican restaurant food and foodways within the organizational setting of the restaurant and the public must be carefully managed by restaurant staff. This raised vigilance produces an organizational culture embedded in a joint practice of maintaining the illusion of authenticity to patrons.

\section{Keywords: Authenticity, Culture, Consumption, Restaurants, Food}

Research concerning the ethnicized structure of the U.S. restaurant industry has typically focused on the commodification of ethnic culture and food as one of the major catalysts in creating the modern multi-billion dollar industry (Gaytan 2008; Chen-Tsang and Lu 2012; Pilcher 2012). Researchers find that a myriad of reasons may be responsible for the rapid growth of the industry. Some scholars point to recent increases in immigration rates from Latin America and Asia to the United States to explain this phenomenon (Mulholland 2007; Pilcher 2014). According to this perspective, recent immigrants longing for nostalgic food and cultural experiences from "back home," drive demand for foods reminscent of their sending country, thus increasing both the importation and popularity of ethnic foods and foodways. More surprising, however, is the perspective that the popularity of ethnic cuisine, particularly Mexican or Chinese, is more of a reflection of the mainstream U.S. consumer base's desire to depart from the generic and to seek out an exotic or foreign experience (Pilcher 2012). 
In an era of globalization, goods, services, and peoples are exchanged at rates never before experienced in the history of the world (Cornell and Hartman 1998; Massey and Sanchez 2006; Jimenez 2009). One must only drive to their local grocery store to be bombarded with advertisements marketing "authentic tortilla chips," "real Indian korma" or their local farmers market for "authentic" local produce and homemade goods. Indeed, in many ways the global exchange of foods and other cultural products has presented rural and urban individuals alike the opportunity to experience ethnic culture and food in the safety of their own community. Early globalization scholars predicted that such a manifestation of globalization would serve to flatten cultural differences between politically and geographically divided regions of the world and would usher in an era of global homogenous culture and ideology (Waters 1990; Ohnuki-Tierney 1994; Sanders 2002). In reality, what has emerged is more representative of the capitalist consumer culture where much like clothing, music, and film, foods represent an opportunity to consume an identity in an increasingly generic world. It is here at the intersection of the democratization of culture, consumerism and modern immigration to the United States that the paradox of authenticity emerges (Cobb 2014).

Individuals venture out in search of the genuine, the pure, the real deal. In other words, the authentic. In many ways, the emergence of "authentic" ethnic food and foodways is a response to market demands. This market demand has produced a powerful industry that has fused global cultures and products with everyday life in the U.S. The invention and incredible popularity of the Mexican taco represents an opportunity analyze this process. According to Pilcher, (2012) the original taco was first a common food in 19th century Mexico City barrios. Initially, varieties of tacos were 
limited. Options ranged from barbacoa (roasted beef or lamb), carnitas (fried or boiled pork) or tripa (tripe and other internal organs). The taco was simply dressed with salsa or in some cases potatoes. In the 20th century, with the increased popularity, the taco began to spread to other parts of the country. As the dish traveled to new regions, it took on the flavors and styles of the localities (Arreola 2004; Pilcher 2012). Carne asada (Sonoran grilled beef) and cochinito pibil (Yucatecan pit-roasted pork) became staples of the regional diets. As an early reflection of the influence of globalization, it was Lebanese immigrants in Mexico which adapted Lebanese cooking traditions to cook Mexican tacos, in this case developing the now popular tacos al pastor (shaved pork) which are highlighted on almost every Mexican restaurant menu in the world. These "Arab" tacos, as they were once called, now occupy a central position in Mexican culture and collective identity.

In the United States, tacos were popular among Mexicans, Mexican Americans, and Anglos as well. In the 1950's upon tasting the taco for the first time, a hotdog vendor from San Bernadino, California, Glen Bell, following the McDonalds model, was inspired to create a chain of restaurants that sold mass produced tacos. The mass production and selling of tacos in the newly established Taco Bell restaurant chain offered patrons exotic foods without the inconvenience, or perhaps even fear associated with traveling to Mexican neighborhoods to get it. It was in this mid-twentieth century development of the fast food taco, that the culinary identies of hard working, poor Mexicans was adapted to fit the American lifestyle (Pilcher 2012). In many ways, the blending of foods and culture forged a symbolic cultural link which remains present in the 21 st century. 


\section{Organizational Defintions}

Buying and selling Mexican food is much more than an economic exchange of goods and services for money. Indeed, any economic exchange represents a symbolic, value-laden transaction influenced by multiple factors such as cultural beliefs, power dynamics, and economic life. (Zeilizer 1994; Velthuis 2005; Carroll and Wheaton 2009). Much research has examined the cultural variables which influence such meaning constructions and how they relate to the contemporary pursuit of authenticity. A small fraction of these studies have focused on how organizational contexts shape presentations and interpretations of authenticity. For instance, Carroll and Swaminathan (2000) examine how microbreweries and beerpubs gain or lose popularity based on the "authentic" appeal of the brewing organization.

More recently, Rao, Monin, and Dur (2005) investigated the tensions between nouvelle and classical French restaurants as they both frame authenticity as an organizational tenet, but present quite different experiences to patrons of their restaurants. Central to all of these studies is the importance of "authentic" claims within organizations. Claims of authenticity have significant economic and social implications. Organizational patterns and dynamics have direct influence on the consumption patterns of clientele. (Lu and Fine 1995; Carroll and Wheaton 2009). That is to say, how a food tastes to a restaurant patron is only one piece of a larger restaurant experience. How a food is cooked, who cooks the food, who serves the food, and what interpretations the restaurant climate generates in patrons are central to claims and challenges to authenticity. In many ways, what becomes perceived and labeled as "authentic" imbues an object with deeper symbolic meaning, and as a result carries with it an almost sacred 
quality to consumers (Frazier, Gelman, Wilson, and Hood 2009; Carroll and Wheaton 2009).

The pursuit of authenticity is shared across industries. Interest in authenticity has been well documented in classical music (Davies 2000), décor (Spooner 1986), and selftaught art (Fine 2003). Even "authentic" furniture (Orvell 1989) has proven to be a highly contested domain. Authenticity is often marked by the presence, or in some cases, glaring absence of cultural artifacts. For instance, many contemporary Hip-Hop recording companies promote a relatively generic offering of song topics and messages. In many cases, the authenticity of a record company or artist is reliant upon their use of violence or weapon oriented themes. Indeed, in such an arena of authenticity, guns and knives serve as authenticity markers (Judy 2004; Samuels 2004; Light 2004). Scholars of authenticity suggest that interest in authenticity is a manifestation of the desire of consumers to classify different forms or art, food, or culture (Baugh 1988; Davies 2001). David Grazian (2003) provides a sociological interpretation of the meaning and pursuit of authenticity in contemporary culture.

According to Grazian, "the ability of a place or event to conform to an idealized representation of reality: that is, to a set of expectations regarding how such a thing should look or feel" is really the product of a series of culturally defined classifications and evaluations (10). Indeed, authenticity can be understood as an agreed upon meaning constructed through interactions between those social actors within organizations producing culture and audiences consuming the meanings and specific products (Douglas 1986; DiMaggio 1987). As one might assume, thus, the determination of authentic values and meanings is a matter of degree of perception. In organizational contexts such as 
ethnic restaurants where authenticity is a contested category, the power to create authenticity does not solely lie with restaurant staff. Rather, staff and patrons of restaurants collaborate on a local, and in many cases, restaurant-by-restaurant basis in order to reach agreement on authentic claims.

\section{Restaurants as Symbolic Cultural Links}

Perhaps no other single cultural domain is so based in notions of authenticity as the modern global restaurant industry. In many ways, food, from its production to its consumption, is a powerful symbol of social and cultural meanings. As a direct expression of group identity and individual subjectivity, foods construct and mark the boundaries of culture, tradition, and authenticity. In many ways, food not only nourishes the body, but also signifies. (Fischler 1988). As one of the most prevalent and observable symbols of the self in society, food and foodways signify distinction and difference between consumers of various types of foods, and legitimize individual claims to authentic presentations of self and identity. What a person eats, and how they eat it provokes an immediate and exceptionally intimate connection to a larger community. As food functions as a means of bringing communities together, it also constructs a seemingly absolute dichotomy of "us" and "them." The politics of food production and consumption represent an opportunity to analyze how foods are assigned meanings in different communities and cultures, and to investigate the ways in which culture, politics, geography, and the economy interrelate to influence food access, food choices, and food significances.

Restaurants function as sites for the public display of ethnic and cultural identities. Often in the case of ethnic restaurants in the United States, they symbolize the boundary 
between private cultural and ethnic customs, and public American practices (Lu and Fine 1995). The dialectic relationship linking explicitly ethnic foods, and an American consumer base which desires a real, or genuine ethnic experience at a restaurant is complicated by the nature of the restaurant business. As businesses, ethnic restaurants must manage their unique displays of taste and style within the bounds of a local environment's order of supply and demand.

A major concern, thus, is the presentation and reception of "authentic" ethnic food and foodways. In order for a restaurant to produce a profit for an owner, it must cater to clientele who oftentimes have little experience with, or knowledge of traditional meals and methods of preparation. As a matter of principle, the level of "authenticity" achievable in a restaurant must always reflect the pallets of consumers who demonstrate their acceptance of a presentation of food with their patronage at a restaurant. As Lu and Fine (1995) make clear, "The success of ethnic food depends on the participation of its audience" (548). Since most ethnic restaurants, particularly those in the Midwestern United States, serve clientele outside of the ethnic group, "authenticity" in taste and style emerges as a constant challenge for owners of Mexican restaurants attempting to accommodate personal cultural traditions with American expectations and pressures.

In regards to a definition of authenticity, this article follows Lu and Fine's (1998) definition of authenticity as "that which is believed or accepted to be genuine or real" (538). An action or a behavior, thus, is only considered to be authentic if it fits within the bounds of an ethnic group's definition of tradition and culture. Clearly, both organizational presentations and definitions of authenticity are highly subjective. Traditions, as well as perceptions of tradition vary from individual to individual, and 
context to context. Traditions vary within ethnic groups based on a slew of factors including geography, politics, social class, and gender (Gaytan 2008). What marks ethnic restaurants as such complex sites for the presentation of public authenticity is the need to earn profit. Many non-ethnic patrons of ethnic restaurants visit ethnic restaurants in order to satisfy a desire for an exotic experience. The function of food to satisfy this need has been coined into the concept of "culinary tourism" (Long 2010). In this sense, patrons of ethnic restaurants desire authenticity within the bounds of American cultural expectations. Eaters do indeed want to experience and taste the exotic, but they do not want to venture too far outside of their comfort zone (Lu and Fine 1998).

\section{Marketing Authenticity and Culture}

The presentation and accomplishment of authenticity is undoubtedly a social construction. Scholars contend that the quest for authenticity is a modern development concerning the effects of globalization and pluralism on individual selfhood and social relationships (Trilling 1971; Handler 1986). Indeed, the presentation of the "ethnic" self symbolizes a form of self-expression which simultaneously serves as a means of defining a boundary between "the collective self and the other" (Ohnuki-Tierney 1993, 3). This, in turn, permits an individual to understand their role in interactions. From this perspective, authenticity relies heavily on the definition of the situation as a "true" experience, person, or event. People, experiences, and events occur in a diverse range of social worlds and contexts.

The presentation of self is political and often based in consumerism. Peterson (1997) found that consumers of country music expected, and desired to see a performer which exemplified their expectations of a representation of their genre's values. As a 
result, country music performers had to consciously modify their aesthetic presentations of self in order to incorporate perceived "authentic" country styles, values and colloquialisms into their music and stage performances. Similarly, Grazian (2004) demonstrated how authenticity is produced and protected in Chicago blue's clubs. In his work, owners of blues clubs consciously sought to capitalize on the aesthetic stereotypes of blues musicians as being Black. To satisfy their predominantly White club patron's desires and expectations, owners exclusively hired Black musicians and Black employees. In this case, race, and more specifically, Black skin served as a signifier of authenticity in the organizational cultural display of Jazz.

In the realm of food, scholars have found that the popular notion, "you are what you eat" carries relevance in the lives of ethnics (Gaytan 2008; Abarca 2004; Fine 1996). "Authentic" ethnic food serves multiple purposes. First, it espouses romanticized ideas of people and places. Second, restaurants which serve the ethnic food provide ethnic raw materials from which patrons can develop an authentic identity. Finally, ethnic restaurants bridge the geographic gap between ethnic and native communities. Often modifying traditional recipes to fit the tastes of local natives, ethnic restaurants typically serve mostly non-ethnic clientele.

\section{Social Organization of Authenticity}

The process of constructing, presenting, and maintaining an illusion of authenticity relies on many individual components. From cooks to servers, and owners to menus, the final presentation of authenticity is reliant on the work and contributions of many parts. Cooks, for example, can vary significantly in their ability to prepare meals. In this case, professional chefs trained in "authentic" preparation may produce a meal much different 
than an ethnic Mexican who based on their lived experiences at home and in the restaurant business believes their style of food preparation best captures "authentic."

Indeed, restaurants like many other businesses experience organizational rhythms. From which cook is preparing the food on a given day, to the server staff on the work schedule, to the aesthetic environment of the restaurant on a given day, the restaurant experience for a patron of the restaurant and the workers themselves can vary significantly. This research seeks to discover the organizational rhythms of Mexican restaurants in order to understand how authenticity is a fluid and context dependent social construction.

\section{A Note on Power in Defining Authenticity}

The ability to label or judge the authenticity of food, an object, or individual is based in power relations. The very word "authentic" is only a few linguistic steps away from the word "authoritarian." In both instances, the words invoke a presumption of a hierarchical narrative of meanings. This is to say, do patrons of restaurants view ethnic cuisine prepared by non-ethnics as authentic, or even partially authentic? Can a Mexican restaurant selling taco "6 packs" with a side of nachos be granted authentic status by ethnics in the community? Perhaps most importantly, in a region of the country with minor Mexican immigrant populations, who has the power to decide what "authentic" means in restaurants?

\section{Method}

The data used for this article were gathered through ethnographic research conducted over approximately two years, beginning in May of 2013 and culminating in March of 2015. Interview data were gathered from 54 restaurants in total, and 
ethnographic research was collected in 12 restaurants. As a participant observer in these 12 restaurants, I volunteered my labor for access to kitchen operations, staff meetings, and workplace interactions. In many ways, I joined the service staff of these restaurants. I performed the duties of busboy, host, table server, bartender, and cook. My tasks as host, busboy, and table server included seating patrons, taking drink and meal orders, explaining dishes, and generally working to please the patrons of the restaurant. As owners and staff at restaurants grew more confident in my abilities to perform tasks, and less concerned with my motives as a researcher in the restaurant, I was gradually granted more responsibilities and authority in the restaurants. This culminated in my responsibility as cook. As a researcher investigating the preparation of "authentic" Mexican food, it was quite shocking to be given the task of cooking food for patrons of the restaurant. Initially, this began with frying chips, blending ingredients for salsa, and culminated with me preparing complex dishes such as chile relleno and enchiladas - the authenticity of which proved fruitful for discussions of what constitutes authenticity among cooks in the restaurants I worked.

Upon entrance to the field I received much resistance from owners and staff of restaurants alike. As an outsider with no credibility in the local restaurant community, I was viewed as suspicious to owners, many of whom continue to avoid me to this day, and as a threat by servers and cooks who felt my presence in the kitchen as a threat to their employment status. Overcoming these barriers proved difficult, but beneficial to the research process. After months, or in some cases, after a year of working at a myriad of restaurants, I was granted access to the intimate community of restaurants. My research on authentic organizational and subjective identities has led me to out of Mexican 
restaurants and into the homes of the local Mexican immigrant community. Access to private parties at restaurants, religious celebrations at homes, and participation in a local Mexican restaurant soccer league has allowed me in a very real way to examine how authenticity in a Mexican immigrant community is accomplished in a restaurant context as well as how the boundaries of authenticity are policed amongst community members in their everyday lives.

My time as an employee and a participant observer totaled approximately 1000 hours. Participant observation was a vital tool for producing a representational description of the social contexts from which ideals of authenticity are produced and reinforced. I worked at least 30 hours at each restaurant which allowed me to conduct research. This auxiliary research was conducted for the purpose of comparison between restaurants. By serving as a participant observer in many different restaurants, I was able to generate common trends in the production process and important distinctions in purposes and visions of restaurants. One restaurant in particular, Paisanos, served as a reference group for all others. At Paisanos, I logged over 500 hours of research. In each setting, I made my role as a social researcher investigating authenticity known to owners and service staff. I was conscious of the negative impact openly taking field notes might have on conversations or interactions at the restaurant, so I used a notepad application on my phone to jot notes in the field. Once I got home, I would elaborate and develop a more complete summary of the day in the field. As a result, my phone had a constant presence in my hand. In fact, I developed a reputation in a few of the restaurants as being a "ladies" man" due to assumptions that I was constantly text messaging women-a 
reputation that proved to be helpful for the field note process and for gaining the trust of restaurant workers.

\section{The Restaurants}

All names used in this dissertation are pseudonyms. Interview data was gathered at 54 restaurants in total. The 54 restaurants were located in three different geographic "zones" I developed during the research process. These zones include the Midwest, the site of all ethnographic research, the Southwestern Borderlands, and Mexico. Upon entrance to Midwestern restaurants, it became clear that geography is, according to restaurant staff, a major barrier to authenticity. I sought to capitalize on this restaurant knowledge by conducting phone and Skype interviews with managerial staff at restaurants across the country and in Mexico in order to generate a comparison of ideologies of authenticity. As a bilingual Mexican American almost all interview and ethnographic data were gathered in Spanish and translated to English for this article. In each zone, I sought to include a range of contexts of restaurants, including urban and rural settings.

Ethnographic data were gathered in Midwestern Mexican restaurants. The 12 restaurants which served as ethnographic sites shared many common traits. The staff was predominantly Mexican immigrants, the language of the kitchen and managerial office was Spanish, and men were almost exclusively the labor force. Most restaurants in the Midwest had generic names based in stereotypical Mexican traditions. The names in the study ranged from El Tequila, Los Mariachis, and Ay Caramba! to Yo Quiero Tacos, Senor Jalapenos, and La Botella. Research gathered at such restaurants was compared to data gathered at the main research site of this project, Paisanos. 
Paisanos, is a family owned restaurant established in 2013. The restaurant was started by the younger brother of a successful Mexican restaurant owner in central Missouri. I began working at Paisanos two months after it opened. The restaurant is family-oriented and located in the middle-class part of town nearby to a local shopping district and movie theatre. The dining area has a large bar and initially consisted of 28 wooden and metal tables, but with increased popularity, has been expanded to 38 darkstained wooden tables. In total, the restaurant can seat 170 people. Two large projection screens and five smaller HD flat-screens adorn the walls of the restaurant and bar area. The menu consisting of traditional Mexican dishes as well as American steaks, burgers, chicken nuggets, and salads average between ten and fifteen dollars per plate. The drink selection was vast and included several domestic and imported draft and bottled beer options as well as a myriad of specialty alcoholic beverages made from spirits. Beer and liquor advertisements are featured heavily on the walls. Pictures of stereotypical Mexican cultural artifacts such as cacti, bulls, and mariachis are sparsely located throughout. A single large black and silver sombrero hangs over the doorway to be used for birthday celebrations. Through my presence at a variety of Mexican restaurants I was also able compare and contrast the different organizational cultures and hierarchical knowledge structures which determined the direction of the displays of authenticity. In total, I have spent over 1000 hours working in the Mexican restaurant community while conducting this research.

Interviews with owners, workers, and patrons of Mexican restaurants strengthen the data gathering process. It was in these semi-structured interviews that I was able to explicitly discuss with patrons and staff at Mexican restaurants their ideologies and 
strategies for constructing, maintaining, and perceiving authenticity. Interviews ranged from 30 minutes to 2.5 hours, depending on the individual. Interviews with owners and staff were conducted at restaurants before or after working hours, and interviews with patrons were conducted at a variety of places ranging from restaurants to libraries, and households. In total, interviews were conducted with 54 owners, 44 staff members (cooks, servers, dishwashers) and 27 patrons of Mexican restaurants.

Content analysis of online restaurant reviews proved to be beneficial in several ways. First, they presented talking points by which interviews with owners and staff of restaurants could respond to claims made in reviews. From complaints of slow service, to compliments for authenticity, reviews allowed for the articulation of organizational goals and expectations in terms of food preparation and presentation. Taken together, these methods of data gathering allowed for the triangulation of data and for a more representational depiction of the organizational experiences of owners, workers, and patrons of Mexican restaurants in the United States.

\section{FINDINGS}

\section{Organizational Rhythms}

As one might expect, the presentation of Mexican authenticity in both food and aesthetics are not static. Rather, everyday organizational cultures and service vary on a day-to-day basis depending on the cook preparing the food, the servers interacting with customers, and even the bartender's choice of music and television programming. While this may seem normal in the case of organizations, it presents a serious issue for owners and managers of Mexican restaurant who desire to present a clear image for a restaurant. The importance of consistency in restaurants is perhaps most important in the kitchen 
where cooks prepare food. Speaking of her difficulties in maintaining this consistency,

Jimena, owner of a large, college student oriented restaurant complained:

You know, it is a big problem for me. I have a cook from one part of Mexico that thinks the food should be cooked his way. Another cook is from a different part of Mexico and thinks the food should be cooked his way. Then I have a cook from Honduras. He is not even Mexican and he thinks the food should be cooked totally different. I have to tell them 'Listen. This is how I want the food cooked.' It's funny but it's not. I don't want my customers to get mad when they order something they like and it comes to them totally different (Jimena, La Llorona Mexican Restaurant).

According to Jimena, unintended organizational rhythms in her kitchen prove to be costly errors at times. She is vigilant of this potential problem and actively seeks to regulate the food preparation process. In this case, the presentation of authentic Mexican food is completely based on the cook for the day. The same dish can be cooked in three different ways with three different ingredients and tastes. Pedro, manager of a small, Mexican immigrant serving restaurant, shares his experiences with this struggle as well. He contends:

When my Mexican customers come in here they don't want to eat food with no flavor. They want food like they get back home in Mexico. I want their business so I need to make them happy. I tell my cooks to make their food more spicy. Instead of green peppers, we put jalapeno peppers in their fajitas. It is not the same as in Mexico, but it is closer.

In this narrative, Pedro makes clear that a variation in food preparation is at times a conscious business decision. In this case, the conscious modification of the menu to include a spicier version of a dish in order to more closely resemble cuisine available in Mexico is aimed at pleasing a customer considered to be an expert in Mexican cuisine. Organizational rhythms are not, however, solely manifested in the preparation of meals. Often, the behaviors and services experiences of restaurant patrons are contingent on management of the restaurant. For instance, most owners and managers had specific 
music genres and songs which they played in the eating area. Songs on these playlists were typically slower, guitar heavy Mexican ballads. These songs of older generations were quickly discarded in the absence of management. Pablo, a young Mexican immigrant with six months of experience working at Paisanos summarized the motives for such behavior.

We get tired of all those old music. My grandparents like. It's okay, but we're not at church. When my boss leaves and I'm in charge, I play better music. Alejandro Sanz, Marco Solís. Nobody complains. I bet they like it more, but the boss picks the music.

Aesthetics play a large role in the restaurant experience. In the case of music selection, a wide range of experiences are provided to patrons of Mexican restaurants. While this form of organizational rhythm is indeed a conscious modification of behavior, it too has the potential to produce negative impacts on the reputation of Mexican restaurants and staff and is therefore a highly policed arena of restaurant life. Indeed, owners and workers alike recognize the differences in their patrons and seek to satisfy the desires of each individual. While certainly an admirable goal, all Mexican restaurants in this study struggled with this issue. The main reason for this struggle is based in the lack of availability of ingredients found in Mexico.

\section{Elements of Authenticity}

The United States and Mexico share a common 3000 mile national border. In locations along this border people and material goods are exchanged freely. Restaurants in this study, however, represent organizations struggling for access to "authentic" elements of authenticity, including ingredients that are not available, too expensive, or even illegal in the United States. For this reason, many owners of Mexican restaurants complained about their lack of ability to follow traditional recipes and to cook "real" 
Mexican food. Payo, a recent immigrant from Mexico and manager of a large Mexican restaurant elaborates on this point. He states:

When I go home I eat everything fresh. Here I cannot get the cheese, the beans, the chiles. How can I cook real Mexican food if I don't have real Mexican food to cook it with? I tried to get the boss to buy from Mexico but he says it is too expensive. I don't understand. I tell him they would laugh at us in Mexico with food like this. He tells me the people who eat here don't know the difference so it doesn't matter.

This quote highlights two major issues. First, Mexican restaurants are first and foremost businesses seeking a profit. Owners seek maximum profit and minimum expenses. This manifests in the form of the use of U.S. bulk packaged foods which cost less than fresh or imported alternatives from Mexico. One might assume that patrons of Mexican restaurants would demand a more representational food product, but given the minimum exposure to Mexican foods and recipes, most Mexican restaurant goers are oblivious to the inauthentic elements used to prepare their meals. An online review of Payo's restaurant, El Jefe's Mexican Food, illustrates this obliviousness. Written online an anonymous reviewer stated:

El Jefe's is the best Mexican food in the area! The prices are good, the food portions are huge, and it all tastes delicious. I've tried Mexican food all over the country and this place has the most authentic everything.

Unbeknownst to the anonymous reviewer of this restaurant, the ingredients which went into making their food can be found at the local bulk food store. Why a person might believe a food which consists of arguably inauthentic ingredients is entirely authentic is directly related to the social environment in which the food is prepared and presented. In this case, the aesthetics of the restaurant.

Perhaps no more obvious example of lacking elements of authenticity can be found in the comments of Gabriela, a Mexican restaurant owner from El Paso, TX. The owner 
of three different Mexican restaurants, Gabriela was eager to share her disgust with the role of state mandates in the preparation and presentation of food in her restaurants.

You need the materia prima (real materials)! The problem is, you can't get that here. The idiots in Austin [TX], say I can't cook with this. I can't get my food from there. It affects the food I serve to my clients. For example, in Mexico you always cook the mole in a special kind of pot. When I tried to do that here they said they were going to shut me down. Too much lead or something like that. That doesn't make any sense. Now, what do I tell my clients? It's ridiculous.

A crucial element of authenticity is undoubtedly the materials which constitute the meal and the tools used to make them. Many of the owners and cooks of Mexican restaurants in the Soutwestern Borderlands and Midwest shared this resentment. Based on state and federal mandates, they were institutionally denied the resources necessary to produce what they felt were "authentically" Mexican food. As businesses however, these two regions differed significantly in their patron experience. In the Borderlands, management sought to maximize the incorporation of elements of authenticity to patrons. As such, music, dress, and language were of the upmost importance. As elements of perceived authenticity, they were consciously policed on an everyday basis. In the Midwest, however, the restaurant experience was quite different. While all restaurants lacked authentic ingredients and methods of preparation, their naïve consumer base did not have the culinary knowledge or experience to challenge the authenticity of the restaurant. As a result, Mexican restaurants in the Midwest did not seek to incorporate the most elements of authenticity as possible as did those in the Borderlands. Rather, Mexican restaurants in the Midwest marketed their food and foodways based in dominant stereotypes of Mexico and Mexican communities in the United States. 


\section{Aesthetics and Pursuit of Profit}

Seeking to capitalize on stereotypes of Mexican culture and restaurants, the management at Paisanos as well as most of the other Mexican restaurants in this study consciously strategized aesthetic decorations in the restaurant. From plates food is served on, to portraits hanging on the walls, to staff uniforms, every decision was made with the intention of presenting an authentic Mexican environment. Given the lack of experience of non-Mexican patrons of Mexican restaurants with Mexican material culture, most "authentic" representations were reduced to stereotypical images commonly associated with Mexico in U.S. popular culture. Therefore, images and figures of tequila bottles, cacti, and various musical instruments dominated the aesthetic terrain of the restaurants in this study. These surface level connections to Mexican culture satisfy an expectation of non-Mexican patrons and cultivate the feeling of an exotic environment. One powerful symbol of national pride very commonly associated with Mexican immigrants in the U.S. is the Mexican flag. Paradoxically, not one flag or image of a flag was found in any of the thirty eight restaurants visited in this study. When asked about the aesthetic terrain of his restaurant, owner Felipe, commented:

I know it's not Mexican. But, when the people come here they say, oh ok, tequila, mariachis, Spanish music, I like this, I'm happy. That is what I want. When the Mexicans come in here they don't care. But if I hang Mexican flags the people would get mad. You can't be patriotic like that. So I do safe and put these things.

Aesthetics, clearly, are an integral component in maintaining the illusion of authenticity. As Felipe and a host of other restaurant owners discussed, the desire to maintain an illusion of authenticity is directly related to the social environment within the restaurant. Patrons enter the Mexican restaurant with well-established expectations of what Mexican culture and restaurants are. In order to keep these customers returning, 
restaurant owners must accept these expectations. Indeed, Mexican restaurant owners not only accept these expectations, they also exploit them. Oscar, the owner or a large Mexican restaurant elaborated on this point. He stated:

Here in this city, people like to watch the sports. So, I put the pictures of the food and the tequila, but I make sure not to get in the way of the televisions. When someone comes here, they want Mexican stuff, but they really want to watch the sports when eating. So, I only have a couple things on the wall. I think the other restaurants will be the same, no? It doesn't matter as long as you have a good game on.

In the case of owners such as Oscar, how Mexican a restaurant looks is not always as important as catering to an American consumer base with a lifestyle based in consuming on average five hours of television every day (Bureau of Labor Statistics 2013). Rather than construct an aesthetic terrain consistent with restaurants in Mexico, owners build the social terrain of their restaurants around the idea of maximum profit. Keeping patrons in their seats, ordering drinks, and coming back regularly all frame the restaurants organizational identity. Tailoring aesthetics as described here by owners succeeds in producing a profit for owners. To stray from this practice, for economic or ethical reasons would almost certainly lead to a decline in sales and patronage at a restaurant.

\section{Conclusion}

The study of ethnic culture and the integration of immigrant communities into mainstream American culture have made considerable advances in recent years. One of the largest advancements has been the recognition that ethnic individuals and communities are dynamic in the sense that traits, characteristics, and practices are by no means fixed, but more fluid in nature. Distinctions which have been historically used to categorize and label ethnic communities have been shown to weaken over time as they 
slowly infuse their receiving communities with their own cultural artifacts. This article has shown that the realm of food is one of the most pivotal and present forms of cultural fusion. As a modern phenomenon, the Mexican restaurant industry has gone global. Mexican restaurants can be found on six continents and in over 150 countries around the world (Pilcher 2012).

What constitutes an authentic ethnic identity or experience is undoubtedly subjective. However, this research indicates that racial and ethnic communities consciously police the boundaries of their groups in very public ways in order to protect the legitimacy of the reputation of an organization, in this case Mexican restaurant, in order to produce and maintain a profit. That is to say, ethnic individuals are cognizant of what they do, why they do it, and how it should be done. It is the purpose of this research to develop an understanding of the personal and organizational cultures of Mexican restaurants in the United States in order to recognize how authenticity in everyday life is visualized, practiced, perceived, and produced. Often, as in the case of Mexican restaurants in this study, authenticity is measured in profit. A restaurant is only as authentic as profits will allow. This relationship between business and aesthetics envelops the organizational culture of Mexican restaurants. Every element and resource which Mexican restaurants utilize directly relate back to their economic potential. 


\section{REFERENCES}

Abarca, Meredith E. 2004. "Authentic or Not, It's Original." Food \& Foodways no. $12(1): 1-25$.

Anderson, Benedict. 1991. Imagined Communities: Reflections on the Origin and Spread of Nationalism. (Revised edition). London; New York: Verso.

Apostolidis, Paul. 2005. Hegemony and Hamburger: Migration Narratives and Democratic Unionism among Mexican Meatpackers in the US West. Political Research Quarterly, 58: 647-670.

Arreola, Daniel (ed.) 2004. Hispanic Spaces, Latino Places: A Geography of Regional and Cultural Diversity. Austin: University of Texas Press.

Banet-Weiser, Sarah. 1999. The Most Beautiful Girl in the World: Beauty Pageants and National Identity. University of California Press.

Baugh, Bruce. 1988. "Authenticity Revisited.” Journal of Aesthetics and Art Criticism 47: 477-487.

Berger, Peter and Thomas Luckmann. 1967. The Social Construction of Reality: A Treatise in the Sociology of Knowledge. Anchor Books.

Blumer, Herbert. 1986. Symbolic Interactionism: Perspective and Method. University of California Press.

Bourgois, Philippe, and Jeff Schonberg. 2007. "Intimate Apartheid: Ethnic Dimensions of Habitus Among Homeless Heroin Injectors." Ethnography 8, 1: 731.

Bureau of Labor Statistics. 2013. "American Time Use Survey."

Carroll, Glenn R. and Anand Swaminathan, 2000, "Why the Microbrewery Movement? Organizational Dynamics of Resource Partitioning in the U.S. Brewing Industry," American Journal of Sociology, 106: 715-762.

Cerwonka, Allaine and Liisa Malkki. 2007. Improvising Theory. Chicago.

Carroll, Glen R, and Dennis Ray Wheaton. 2009. "The Organizational Construction of Authenticity: An Examination of Contemporary Food and Dining in the U.S." Research in Organizational Behavior, 29:255-282. 
Cornell, Stephen and Douglas Hartmann. 1998. Ethnicity and Race: Making Identities In a Changing World. Thousand Oaks, CA: Pine Forge Press.

Crenshaw, Kimberle W. 1991. "Mapping the Margins: Intersectionality, Identity Politics, and Violence against Women of Color." Stanford Law Review, 43, 6: 1241-1299.

Davies, Stephen. 2001. Musical Works and Performances: A Philosophical Exploration. Oxford: Clarendon Press.

Davila, Arlene. 2001. Latinos, Inc.: The Marketing and Making of a People. University of California Press.

DiMaggio, Paul. 1987. "Classification in Art." American Sociological Review 52: 440-455.

Douglas, Jack D. 1970. (ed.) Understanding Everyday Life. Chicago: Aldine.

Douglas, Mary. 1986. How Institutions Think. Syracuse: Syracuse University Press.

Fine, Gary Alan. 1996. Kitchens: The Culture of Restaurant Work. Berkeley: University of California Press.

Fischler, Claude. 1980. "Food, Self, and Identity." Social Science Information, 27: 275-292.

Gaytán, Marie Sarita. 2008. "From Sombreros to Sincronizadas Authenticity, Ethnicity, and the Mexican Restaurant Industry." Journal of C Contemporary Ethnography no. 37

Geertz, Clifford. 1973. The Interpretation of Cultures. New York: Basic Books.

Gergen, Mary M., and Gergen, Kenneth J. 1993. "Narratives of the Gendered Body in Popular Autobiography." In The Narrative Study of Lives. Sage Publications.

Gerth, H. H. and C. Wright Mills, ed. 1946. From Max Weber: Essays in Sociology. New York: Oxford University Press.

Goffman, Erving. 1959. The Presentation of Self in Everyday Life. Doubleday.

Gordon, Steven L. 1981. "The Sociology of Sentiments and Emotion" in Social Psychology: Sociological Perspectives. New York: Basic Books.

Grazian, David. 2005. Blue Chicago: The Search for Authenticity in Urban Blues Clubs: University of Chicago Press. 
Gubrium, Jaber and James Holstein. 2011. Forthcoming in Sage Handbook of Qualitative Data Analysis, edited by Uwe Flick. London: Sage.

Gubrium, Jaber F. and James A. Holstein. 1999. The Self We Live By: Narrative Identity in a Postmodern World. London: Oxford University Press.

Hall, Stuart. 1996. "The Problem of Ideology: Marxism Without Guarantees." in Stuart Hall: Critical Dialogues in Cultural Studies, edited by D. Morley and K-H. Chen. Routledge.

Harbison, Sarah F. 1981. Family Structure and Family Strategy in Migration Decision Making. New York: Center for Cultural and Technical Interchange between East and West, Inc.

Hochschild, Arlie. 1983. The Managed Heart. University of California Press.

Jimenez, Tomás R. (2010) “Affiliative Ethnic Identity: A More Elastic Link Between Ethnic Ancestry and Culture" Ethnic and Racial Studies, 33(10): 17561775 .

Jimenez, Tomas. 2009. Replenished Ethnicity: Mexican Americans, Immigration, and Identity. Berkeley, CA: University of California Press.

Judy, R.A.T. 2004. "On the Question of Nigga Authenticity.” Pp. 105-118 in Murray Forman and Mark Anthony Neal (eds.), That's the Joint: The Hip- Hop Studies Reader. New York: Routledge.

Karner, Christian. 2007. Ethnicity and Everyday Life. Routledge.

Karp, David A., and Yoels, William C. 1993. Sociology in Everyday Life. Itasca, IL: Peacock.

Lamont, Michele. 2000. The Dignity of Working Men. Harvard.

Light, Alan. 2004. “About a Salary or Reality---Rap's Recurrent Conflict.” Pp. 137147 in Murray Forman and Mark Anthony Neal (eds.), That's the Joint: The Hip-Hop Studies Reader. New York: Routledge.

Long, Lucy M. 2013. Culinary tourism: University Press of Kentucky.

Lu, Shun, and Gary Alan Fine. 1995. "The presentation of ethnic authenticity." The Sociological Quarterly no. 36 (3):535-553.

Macias, Thomas. 2004. "Imaginandose Mexicano: The Symbolic Context of Mexican American Ethnicity Beyond the Second Generation." Qualitative Sociology 27(3) 199-315. 
Massey, Douglas S. and Magaly Sanchez R. 2006. "Latino and American Identities as Perceived by Immigrants." Qualitative Sociolology 30:81- 107.

Mead, George Herbert. 1967. Mind, Self and Society. University of Chicago Press.

Min, Pyong Gap. 2010. Preserving Ethnicity Through Religion in America: Korean Protestants and Indian Hindus Across Generations. New York: New York University Press.

Mulholland, Mary-Lee. 2007. "Mariachi, Myths and Mestizaje: Popular Culture and Mexican National Identity." National Identities, 9 (3): 247-264.

Ohnuki-Tierney, Emiko. 1994. Rice as self: Japanese identities through time: Princeton University Press.

Orvell, Miles. 1989. The Real Thing: Image and Authenticity in American Culture: 1880-1940. Chapel Hill: University of North Carolina Press.

Peterson, Richard A. 1997. Creating country music: Fabricating authenticity: University of Chicago Press.

Pilcher, Jeffrey M. 2012. Planet Taco: A Global History of Mexican Food. London: Oxord University Press.

Pilcher, Jeffrey M. 2014. “'Old Stock’ Tamales and Migrant Tacos: Taste, Authenticity, and the Naturalization of Mexican Food." Social Research, Summer 2014: 441-462.

Ronai, C.R. 1992. "Seperating Aging From Old Age: The Aging Table Dancer." Journal of Aging Studies, 6,4.

Rose, Nikolas. 1998. Inventing Our Selves. Cambridge University Press.

Said, Edward. 1979. Orientalism. New York Vintage Books.

Samuels, David. 2004. “The Rap on Rap: The 'Black Music' that Isn't Either.” Pp. 147-154 in Murray Forman and Mark Anthony Neal (eds.), That's the Joint: The Hip-Hop Studies Reader. New York: Routledge.

Sanders, Jimy M. 2002. "Ethnic Boundaries and Identity in Plural Societies." Annual Review of Sociology, 28:327-57.

Smith, Dorothy E. 2005. Institutional Ethnography: A Sociology For People. Lanham, MD: AltaMira Press. 
Spooner, Brian. 1986. "Weavers and Dealers: The Authenticity of an Oriental Carpet." Pp. 195-235 in Arjun Appadurai (ed.), The Social Life of Things: Commodities in Cultural Perspective. Cambridge: Cambridge.

Steinberg, Stephen. 1981. The Ethnic Myth: Race, Ethnicity and Class in America. Boston, MA: Beacon Press.

Stoler, Laura A. 2002. Carnal Knowledge and Imperial Power. California.

Swidler, Ann. 1986. "Culture in Action: Symbols and Strategies." American Sociological Review, 5 1(2).

Telles, Edward and Vilma Ortiz. 2009. Generations of Exclusion: Mexican Americans, Assimilation, and Race. New York: Russell Sage Foundation.

Trilling, Lionel, and Lionel Trilling. 2009. Sincerity and authenticity: Harvard University Press.

Waters, Mary. 1990. Ethnic Options: Choosing Identities in America. Berkely, CA: University of California Press.

Van Maanen, John. 2011. Tales of the Field. University of Chicago Press.

Velthuis, Olav. 2005. Talking Prices: Symbolic Meanings of Prices on the Market for Contemporary Art. Princeton: Princeton University Press.

Yang, Fenggang and Helen Rose Ebaugh. 2001. Transformations in New Immigrant Religions and Their Global Implications. American Sociological Review 66:269288.

Zelizer, Viviana A. 1994. The Social Meaning of Money. New York: Basic. 


\section{CHAPTER 3}

\section{HYBRID MASCULINITY IN MEXICAN RESTAURANT WORK}

Abstract: In many restaurants across the United States, Mexican immigrant labor satisfies the high demand for low skilled service industry workers. Based on two years of participant observation and open-ended interviews in Mexican restaurants located in the Midwest, this article explores the gendered niche of male Mexican restaurant cooks and servers. Traditionally marked as women's work, restaurant food preparation and serving is almost exclusively a male dominated economic sector. This article introduces the concept of gender posturing as a means of developing a pragmatic understanding of the many ways male restaurant workers define, perform, negotiate, and police the boundaries of acceptable forms of masculinity while simultaneously performing traditional feminine work in a socially constructed workplace in which masculinity is of premium importance.

Keywords: Authenticity, Gender, Performativity, Masculinity, Restaurants,

One of the major questions regarding the debate over Mexican immigration to the United States is the overall impact these immigrants have on the economy. Since most Mexican immigrants migrate to the United States in order to attain work, the placement of these immigrants has an immediate and direct effect on local labor forces as well as the range of options of goods and services available for local and mainstream American consumers. As a result, the discourse on immigrant impact on the United States has expanded to include concerns over the cultural integrity of the nation. Notions of borders under attack, jobs being stolen, and immigrant gangs degrading the moral and social infrastructure of the United States have quickly emerged in mainstream narratives and opinions of Mexican immigrants across the country.

Paradoxically, fears and concerns over the social and economic changes occurring in the U.S. have occurred concurrently with a boom in the Mexican restaurant industry. Relatively unknown to the palate of most Americans prior to the 1970's, Mexican food now occupies a central location in the mainstream culinary diets of most Americans. In addition to the many Mexican restaurants being established across the country, Mexican 
food has found its way into school lunch menus, military cafeterias, and the world of fast food.

\section{Migrant Labor In a Globalized World}

The emergence of a globalized world economy has linked economic markets, technologies, and international governing bodies. Simultaneously, the implementation of neo-liberal legal doctrines directly effecting an individual's right to mobility has made possible vast migrations of individuals seeking paid employment on a scale never before seen in history. Individuals migrate for a myriad of reasons. Some migrants desire to escape from destitute conditions, particularly caused by war or famine, in their home country (Steinberg 1981; Massey and Sanchez 2006). Others facing unemployment seek to provide a more significant income for their families back home. Indeed, unemployment and poverty in underdeveloped countries across the globe serve as push factors for migrants seeking economic opportunities (Yang and Ebaugh 2001; Jimenez 2009).

Migrant workers provide a positive boost to the economy of their host countries, and the remittances which are sent back home to family members help to boost the local economies of their countries of origin. Despite a global economic recession, Latin American immigrants sent USD 58.9 billion to their transnational communities in 2011 (Cohen 2011). Migrant workers and their families have little control over their lives and often have no legal or social protection making them susceptible to exploitation and human trafficking. Highly skilled migrant workers have more control over their participation in the labor force and are at much less of a risk to exploitation by employers. However, the large migration of highly unskilled laborers from 
underdeveloped countries to developed countries has led to the exploitation of millions of individuals. The International Labor Organization (ILO) has made efforts to impose global standards on such forms of migration and exploitation for both migrant sending and receiving countries in an effort to manage migration flows and protect this considerably vulnerable category of workers and their families (Dauvergne 2008 ;Massey 2002).

The demand for migrant labor in developed countries has drawn tens of millions of migrant workers from their home countries and into the low skill labor force of developed countries. Current estimates of the global migrant population approximate the population to be 175 million individuals (Christ 2015). Women compose half, or approximately 87 million, of all migrant workers. While both male and female migrant workers satisfy the demand for cheap labor in developed nations, they do so in variable ways. Consistent with widespread philosophies of masculinity and femininity, men assume positions in the manual labor economy, including construction, animal processing, and agriculture. Women are predominantly tracked into the service industry and are typically employed as nannies, maids, and embroidery work.

In many Mexican restaurants across the United States, preparing and serving food has emerged as a gendered occupational niche for Mexican immigrant men. As part of a larger ethnographic research project on the social organization of authenticity, this article draws on two years of participant observation in Mexican restaurant kitchens in the Midwestern United States to examine the social construction of masculinity among Mexican immigrant men performing traditional women's work. On a daily basis, restaurant workers perform gender and police the boundaries of masculinity. 
With the recent boom in ethnic restaurants in the United States, kitchen work has emerged as a well-studied arena of social life. These studies highlight the intersections of race/ethnicity, culture, and the economy. In many ways, restaurants function as sites for the public display of ethnic and cultural identities. Often in the case of ethnic restaurants in the United States, they symbolize the boundary between private cultural and ethnic customs, and public American practices (Lu and Fine 1995). However, while existing studies have done well to demonstrate the social structure of restaurants and the emotional labor that goes into establishing and maintaining relationships with coworkers and restaurant patrons, few studies have explored the gendered dimension of Mexican restaurants in the United States, an arena almost exclusively dominated by Mexican immigrant men.

In this study, I pose the following questions: Among Mexican immigrant men working in restaurants, how is masculinity defined? How is masculinity performed for others? To what extent, and in what ways, do Mexican immigrant men working in restaurants police the boundaries of acceptable masculinity? In sum, to what degree is masculinity sought and challenged in the everyday work lives of Mexican men performing traditionally women's work. I use the phrase “women's work" to summarize the range of domestic tasks, such as cooking, cleaning, and serving others, typically assigned to women in societies such as Mexico based in traditional gender ideologies. While a growing field of research demonstrates that a significant proportion of contemporary migrant laborers are women, this article focuses on a realm of work that, up to this point, is dominated almost exclusively by men. How Mexican immigrant men 
performing such tasks manage a sense of masculine identity is, thus, an exercise in understanding modern social constructions and performances of masculinity. Identity and the Self

Scholars of identity are well aware that an identity, such as Latino/a, is flexible, situational oriented, and contingent on the definition of the situation (Jimenez 2010; Gans 1979; Thomas 1923). A growing literature on the sociology of immigrant identity seeks to understand the trends in the construction of identity among Latino/a communities (Vasquez 2010; Jimenez 2009; Gutierrez 2005). This has led to a series of explanations which differ in their justification of how and why Latino/as identify as they do. Latino/a identity can become symbolic when there is a large gap between immigrants, their descendants, and their point of origin (Jimenez 2009; Waters 1990; Gans 1979), Latino/a identity can be a reaction to external pressures (Min 2010; Portes and Rumbaut 2001), Latino/a identity may be revived during social movements (Nagel 1997), and Latino/a identity can assume more of a panethnic perspective as diverse populations come together around a single phenomenon such as racialization (Espiritu 1992).

How we come to define ourselves is an extremely social process (Gubrium and Holstein 2003; Mead 1967; Goffman 1959). As personal as we may assume our conceptions of who we are, what we like, and what we do might be, all of these perceptions and ideals are constructed in relation to institutional and cultural discourses. That is to say, social actors rely on social interactions with others to learn about and engage with various categories of identity construction. In turn, our social interactions with others serve to confer our presentations of self (Goffman 1959). The self and identity are two very similar, yet subtly distinct concepts. To be clear, the self is the 
constructed subject we conceive ourselves as, and an identity is a shared label used to identify a self (Gubrium and Holstein 2003).

Articulations of the self result in the development of groups, communities and macro structures (Sewell 1992; Bourdieu 1984; Berger and Luckman 1967). In turn, these socially constructed structures influence the creation of an identity by providing a system of shared meanings (for example, language) through which an individual can use a guide to take the role of the other, reflect on the self as an object, and engage in social interactions (Blumer 1989; Mead 1967; Cooley 1902). Social interactions serve as opportunities for us to receive feedback on how we are presenting our selves, receive approval of an identity, and confirm our own beliefs of who we think we are (Blumer 1989; Goffman 1959; Cooley 1902). Social interactions occur in a wide variety of contexts.

Relevant to the sociology of identity is the common character of all social interactions that interactions occur between individuals who occupy specific positions or who possess certain statuses (Rose 1998). That is to say, a social interaction is not the converging of two individuals, but rather, specific dimensions of two individuals who possess membership to a certain group or status - their identity (Burke 1980). While the sociology of identity is a broad field which examines individual and collective forms of identity, this article is based on a series of foundational theories of identity as they relate to masculinity and identity in Mexican and Mexican American communities. As Mexicans constitute a unique case of a mobile migrant population numbered in the millions, this article has significant implications for the understanding of the social 
construction of masculinity and identity in Mexican immigrant communities in the United States.

\section{Understanding Latino/a Identity}

An ethnic group can be defined as a collective of individuals within larger society who share a common ancestral origin, culture, and history (Cornell and Hartman 1998). In this sense, Latino/a identity is not something which is inherited, but rather is something which is achieved through socialization and enactment of cultural cues. (Jimenez 2010; Brubaker et al. 2007). Undeniably, the salience of the Latino/a identity is dependent on the context and can manifest in "thick" or "thin" forms. (Cornell and Hartman 1998). The contexts which produce this variance have been the site for rigorous study in recent years. As a result, there are many competing frameworks which Latino/a identity theorists suggest best apply to the population.

\section{Masculinity and Mexican Men}

Masculinity is a social construction. The cultural significance of masculinity, and how it is performed across spaces and places, is a case example of how normative behavior varies between cultures and over time (Connell 2000; Kimmel 2006). Moreover, masculinities are the products of complex, contradictory, and dynamic social interactions between men and women of varying power relations (Ramirez 2011). A growing body of gender studies has questioned the cultural stereotype of machismo (Mirande 1997; Abalos 2002; Irwin 2003). In stereotypical terms, machismo is often defined as the struggle for power between men and the domination of women (Chant and Craske 2003; Ramirez 2011). In many ways, machismo has been shown to not only be an exercise of 
power and authority over women, but also as a case of men oppressing other men who are not deemed to possess socially acceptable masculinity.

More recent studies of gender constructions and influences on everyday life among Mexican men and women have demonstrated a more nuanced model of masculinities wherein men and women are not purported to fit two monolithic and dialectic groups, but rather capable of occupying a liminal space somewhere on this spectrum of gendered performativity possibilities. Indeed, as Gutman (1996) makes clear, many Mexican men see themselves ni macho ni mandolin (neither macho nor apron wearing). While it may be true for many Mexican immigrant men in the United States who embrace "ranchero masculinity," as a result of their socialization, research has consistently shown that gender, and more specifically, masculinity, is a fluid social construction which, on a pragamatic level, adapts to social environments and influences (Smith 2003, 2006).

Previous theories of Latino masculinities have been repeatedly challenged by scholars who point to masculine roles and identities as being shaped by social context, in particular, by one's relationship to authority in a social hierarchy, geography, and exposure to mainstream U.S. influences (Baca Zinn 1982; Ramirez 2011). Indeed, as immigrants navigate their new social contexts, the norms and cultural frameworks which define their everyday lives are subject to external hegemonic pressures.

Where an immigrant works is one such context where structural forces influence their perception of their own identity and of others. Much research has demonstrated that workplaces are prime locations of where gender identity work occurs. Indeed, gender identities are often constructed, validated, challenged, and renegotiated on a daily basis in 
workplace environments (Kimmel 2000; Messerschmidt 2004; Ramirez 2011). Securing and maintaining employment is a key concern for Mexican migrant laborers who travel thousands of miles, in some cases undocumented, in order to sell their labor, save money, send remittances to friends and family in Mexico, and achieve upward social mobility (Massey and Sanchez 2006; Telles and Ortiz 2009).

Once in the United States, Mexican immigrant men often find themselves in a racially and sex segregated occupation (Ramirez and Hondagneu-Sotelo 2009; Ramirez 2011). Indeed, the availability of jobs in construction, agriculture, and animal processing plants is commonly attributed with the increase of outward migration from the Mexico, the Southwest, and the development of immigrant communities in rural area across the United States (Kandel and Gibbs 2004). While these occupations, which do rely on hard work and physical prowess, represent a traditional form of gendered work, research has shown that contemporary Mexican immigrant men satisfying this demand for labor do not exactly fit the stereotypical working class masculinity model. This research seeks to add to this discussion by exploring the understudied world of Mexican immigrant men performing restaurant work. This arena of study represents an opportunity to understand the forms and facets of masculinity which arise on a daily basis as men engage in traditional women's work.

Below, I describe my field sites, my experiences interacting with owners and staff members of Mexican restaurants, and the methodological process through which data was gathered. I then describe the central themes of gender performances in restaurants and everyday lives of Mexican immigrant men using data from my field research to illustrate my argument. 


\section{Method}

The data used for this article were gathered through ethnographic research conducted over approximately two years, beginning in May of 2013 and culminating in March of 2015. Interview data were gathered from 54 restaurants in total, and ethnographic research was collected in 12 restaurants. As a participant observer in these 12 restaurants, I volunteered my labor for access to kitchen operations, staff meetings, and workplace interactions. In many ways, I joined the service staff of these restaurants. I performed the duties of busboy, host, table server, bartender, and cook. My tasks as host, busboy, and table server included seating patrons, taking drink and meal orders, explaining dishes, and generally working to please the patrons of the restaurant. As owners and staff at restaurants grew more confident in my abilities to perform tasks, and less concerned with my motives as a researcher in the restaurant, I was gradually granted more responsibilities and authority in the restaurants. This culminated in my responsibility as cook. As a researcher investigating the preparation of "authentic" Mexican food, it was quite shocking to be given the task of cooking food for patrons of the restaurant. Initially, this began with frying chips, blending ingredients for salsa, and culminated with me preparing complex dishes such as chile relleno and enchiladas - the authenticity of which proved fruitful for discussions of what constitutes authenticity among cooks in the restaurants I worked.

Upon entrance to the field I received much resistance from owners and staff of restaurants alike. As an outsider with no credibility in the local restaurant community, I was viewed as suspicious to owners, many of whom continue to avoid me to this day, and as a threat by servers and cooks who felt my presence in the kitchen as a threat to their 
employment status. Overcoming these barriers proved difficult, but beneficial to the research process. After months, or in some cases, after a year of working at a myriad of restaurants, I was granted access to the intimate community of restaurants. My research on authentic organizational and subjective identities has led me to out of Mexican restaurants and into the homes of the local Mexican immigrant community. Access to private parties at restaurants, religious celebrations at homes, and participation in a local Mexican restaurant soccer league has allowed me in a very real way to examine how authenticity in a Mexican immigrant community is accomplished in a restaurant context as well as how the boundaries of authenticity are policed amongst community members in their everyday lives.

My time as an employee and a participant observer totaled approximately 1000 hours. I worked at least 30 hours at each restaurant which allowed me to conduct research. This auxiliary research was conducted for the purpose of comparison between restaurants. By serving as a participant observer in many different restaurants, I was able to generate common trends in the production process and important distinctions in purposes and visions of restaurants. Once restaurant in particular, Paisanos, served as a reference group for all others. At Paisanos, I logged over 500 hours of research. In each setting, I made my role as a social researcher investigating authenticity known to owners and service staff. I was conscious of the negative impact openly taking field notes might have on conversations or interactions at the restaurant, so I used a notepad application on my phone to jot notes in the field. Once I got home, I would elaborate and develop a more complete summary of the day in the field. As a result, my phone had a constant presence in my hand. In fact, I developed a reputation in a few of the restaurants as being 
a "ladies' man" due to assumptions that I was constantly text messaging women-a reputation that proved to be helpful for the field note process and for gaining the trust of restaurant worker.

\section{The Restaurants}

Interview data was gathered at 54 restaurants in total. The 54 restaurants were located in three different geographic "zones" I developed during the research process. These zones include the Midwest, the site of all ethnographic research, the Southwestern Borderlands, and Mexico. Upon entrance to Midwestern restaurants, it became clear that geography is, according to restaurant staff, a major barrier to authenticity. I sought to capitalize on this restaurant knowledge by conducting phone and skype interviews with managerial staff at restaurants across the country and in Mexico in order to generate a comparison of ideologies of authenticity. As a bilingual Mexican American almost all interview and ethnographic data were gathered in Spanish and translated to English for this article. In each zone, I sought to include a range of contexts of restaurants, including urban and rural settings.

Ethnographic data were gathered in Midwestern Mexican restaurants. The 12 restaurants which served as ethnographic sites shared many common traits. The staff was predominantly Mexican immigrants, the language of the kitchen and managerial office was Spanish, and men were almost exclusively the labor force. Most restaurants in the Midwest had generic names based in stereotypical Mexican traditions. These names ranged from El Tequila, Los Mariachis, and Ay Caramba! to Yo Quiero Tacos, Senor Jalapenos, and La Botella. Research gathered at such restaurants was compared to data gathered at the main research site of this project, Paisanos. 
Paisanos, is a family run restaurant established in 2013. The restaurant was started by the younger brother of a successful Mexican restaurant owner in central Missouri. I began working at Paisanos two months after it opened. The restaurant is family-oriented and located in the middle-class part of town nearby to a local shopping district and movie theatre. The dining area has a large bar and initially consisted of 28 wooden and metal tables, but with increased popularity, has been expanded to 38 dark-stained wooden tables. In total, the restaurant can seat 170 people. Two large projection screens and five smaller HD flat-screens adorn the walls of the restaurant and bar area. The menu consisting of traditional Mexican dishes as well as American steaks, burgers, chicken nuggets, and salads which averaged between ten and fifteen dollars per plate. The drink selection was vast and included several domestic and imported draft and bottled beer options as well as a myriad of specialty alcoholic beverages made from spirits. Beer and liquer advertisements are featured heavily on the walls. Pictures of stereotypical Mexican cultural artifacts such as cacti, bulls, and mariachis are sparsely located throughout. A single large black and silver sombrero hangs over the doorway to be used for birthday celebrations.

\section{FINDINGS}

\section{Men as Competitors}

My initial excitement and high hopes for gathering data in Mexican restaurant kitchens were quickly replaced with disappointment and discouragement. Despite the camaraderie I was able to develop with restaurant owners, my many efforts to break the ice with restaurant staff failed. I was repeatedly left out of conversations and treated with suspicion. At first, this made me quite uncomfortable. I did not understand why I was 
such an outsider in a community of individuals with whom I shared so many

characteristics. I had assumed that speaking fluent Spanish, being the descendent of recent immigrants from Mexico, and being an able bodied male in a male dominated space that I would be seen as an insider. The obvious discomfort with my presence of staff in kitchens is illustrated by this excerpt from my field notes:

I started working at 3PM today. It was just me and Oscar in the kitchen for a couple hours preparing ingredients for the dinner rush to come. In the whole time we worked until the dinner staff arrived, we spoke only one time about how to turn on the deep fryer. He seems to avoid me and I think he is holding back helpful information as to how to get things done in the kitchen.

A few weeks later, a new server, Chucho, joined the restaurant staff. Coming from Mexico, it was his first time in the United States. Chucho is a kind and outgoing individual who is easy to get along with. I watched as he, just as I had been, was relegated to the social periphery of the kitchen. It was in this reaction to Chucho joining the restaurant work staff that I had the realization of why he and I were seen with such suspicion. In many ways we were not only interpreted as threats to the job security of existing workers, but also as competitors taking the highly sought after tips left by restaurant patrons.

A few days after Chucho's arrival a large snow storm hit the area knocking out the satellite signal of the restaurant. As the newest members of the staff and, thus, occupants of the lowest rungs on the social hierarchy of the restaurant, Chucho and I were assigned the task of scaling the side of the restaurant with a 6 foot ladder and clearing the snow debris from the satellite dish. As we prepared to climb the ladder in the snow storm, I asked Chucho why he wasn't wearing a coat. "I don't have one," he said. Shocked, and more prepared to handle the winter weather, I took the lead. As I pulled 
Chucho up to the roof, I could sense that he was worried. Having no experience with snow and ice, he took a couple steps on the roof and quickly fell hard on his back. I ran to help him up and saw tears welling up in his eyes. "They are trying to make me quit," he yelled. Who is, I asked.

"All of them. Ever since I got here they have been giving me a hard time. They don't talk to me. They won't explain how the boss wants the job done. Yesterday, they didn't tell me they were leaving for work and so I had to walk here because they left me."

Chucho's experiences were not unique in any way. The servers earned no hourly wage working at the restaurant. Rather, all of their earnings came from tips from patrons. As such, competition for tips was constant. After announcing to the group that I am not a paid worker and that any tips I get would be shared with everyone in the kitchen, I was able to share conversations, meals, and personal stories with staff members. Many of my early conversations revolved around the hazing of new employees. Pedro, a middle aged heavy set man from Guanajuato, Mexico was eager to share his stories with me.

When I first got here, they were brutal to me. I wasn't working in this restaurant, a different one here in town. When I would be serving the food to people, they would try to trip me. I never dropped the plates but I almost did. One day when I was cleaning a table I had my knee on the seat and was underneath picking up the food. One of the other servers came behind me and rammed me in the butt. I fell forward onto the chair and ended up under the table with the trash. It made a loud noise and everyone was looking at me. My boss came over and after we cleaned it up he yelled at me in the kitchen and told me if I did it again, I would be fired. I never trusted those guys. That's why I left.

According to Mexican masculinity scholar, Hernan Ramirez (2010), Mexican manhood is often measured by an individual's ability to earn money and provide for family members. In other words, real men are expected to be breadwinners. This key trait of masculinity in Mexican spaces in many ways is what drives competition and suspicion among restaurant workers. Every new member of restaurant staff has the potential to replace an existing 
member of the staff and to emasculate them by reducing their ability to provide for their families.

Over the course of my time in restaurant kitchens, I was exposed to many of these tensions. Friday nights were often the most profitable for restaurant owners and servers. Many young and affluent college students would stop by the restaurant before or after their trip to the movie theatre located across the street. For this reason, Friday nights were the most coveted night to be scheduled to work. For servers fortunate enough to be scheduled, a competition for tables drove the tensions all night. One night after he felt he was repeatedly passed over for tables by the cousin of the manager, a younger staff member named Jose, Rico, a server for four years at Paisanos exploded in rage:

Why do you keep giving him all the tables!? We are supposed to have the same amount and I have counted, he has seven more than me.

Reaching into his pockets, Rico pulls out two handfuls of crumpled bills, all of his tips for the night, and hold them in the face of the manager.

Look at this. This is nothing. I have been working here for five hours and this is all I have. You keep sending people to his tables. Tell me why. Tell me why. I have a boy to feed. I have a wife to feed. I need this. You and him always want to joke and waste time, but I need this money.

The manager, Jose, a 15 year local high school dropout and nephew of the owner is visibly shaken. "I don't know what he is so mad about," he tells me. "The people sit where they want, I don't force them." Later in the evening as the crowd dies down, Rico opens up to me.

If I don't say anything when they do that shady stuff to me, they will take all my money and I can't let that happen. My son is eight years old and is still in Mexico. I have not seen him in five years since I got here. If I don't send him money, what is he going to eat? I don't do this because I like it, I do it because it is the only way to take care of him. 
Being able to provide for family members was central to claims of authentic manhood in many of the kitchens in which I worked. Whether young or old, servers felt a responsibility to provide for their families, and at the same time were very willing to share their contributions publically to anyone who would listen. Perhaps no better example of this public display of masculinity through financial support is an older restaurant worker named, Diego. According to his personal accounts, Diego was a former senator in his native county of Guatemala before migrating to the United States in search of employment. Along with many stories about how the Russians have seen the City of God on Saturn but are hiding it from people, and tales of his speeches to thousands of devoted followers in his hometown, Diego was constantly announcing how and why he sent money back home to family. One day in particular, Diego walked into the restaurant kitchen a bit more chipper than usual. He found a seat watching the group of us cut tomatillos, and with an obviously fake sigh started talking.

I just sent back another $\$ 500$ today. My daughter is going to take all my money. She called me yesterday saying her mother was upset that they didn't have a good phone. I told them it was not a big deal, but they wouldn't drop it. That's almost $\$ 2000$ that I have sent back already this year and it is only June! I told them I am working as hard as I can. I can't keep sending them so much money. I have bills here, you know. Who am I kidding, though? I know I am going to send them a few more hundred when I get paid next week. I'm just too nice. That's why they always call me daddy.

While everyone who listened to Diego on that day or any other knew he was showing off, and in some ways, doubted the validity of his stories, the idea that real men provide their families with money and gifts was a dominant cultural narrative which everyone shared. For that reason, Diego and anyone else who was able to send remittances to family was put in high esteem. For younger restaurant staff that did not have children and were more interested in spending their money on cars, fashion, and girlfriends, respect and status in 
the kitchen was much harder to achieve. In order to compensate for this lack of manhood, many younger restaurant workers turned to public displays and discussions of their sexual prowess in order to impress other and to be treated as real men.

\section{Real Men Chase Women}

After a few months of working at Paisanos, I was able to begin developing friendships with restaurant management and staff. Going deeper than surface level interactions about the weather or sports, I began to get to know the workers on a personal level; and they began to ask questions about my personal life. The question of whether or not I had a wife or girlfriend was almost always the first get-to-know-you question I was ever asked. Recognizing that relationships with women was a pillar of the traditionally heteronormative construction of Mexican masculinity, I did share that I had a wife. As a result, on several occasions I was asked to bring my wife to a party or celebration. Over the course of my fieldwork, my marriage became public knowledge and the basis for much conversation. In many ways, my credibility and status as a man benefited. Kitchen conversations were often framed around the ups and downs of dating. More specifically, the sexual conquests from the previous night or ones anticipated in the near future seemed to help restaurant staff pass the time.

One busy Saturday evening I walked back into the kitchen to ask the cook to redo the order of a customer had requested a specialization which was not made correctly. From across the kitchen I could see Eric, the head cook and a Mexican immigrant in his late 20's who has worked at the restaurant for three years, with one foot on the floor and the other planted firmly on the edge of the deep fryer. As he carefully tumbled the cooking tortilla chips in the deep fryer so as to ensure none would burn or stick to each 
other, he thrust his hips back and forth making a moaning sound. "Look! This is how I do it. This is how my ladies like it," he exclaimed proudly. Not to be outdone by Eric's display of sexual prowess, Gus, a Mexican immigrant in his early 40's who normally works as a bartender but helps to cook on busy weekends, quickly plants his foot on the edge of the deep fryer next to Eric's. 'No, you're doing it wrong. You need to go slower. Trust me, my friend. If you do it like this, they will keep calling you more and more.” In what I would describe as a homoerotic thrusting competition, Gus and Eric pumped their hips forward and backward for at least five minutes asking each member of the service staff who entered the kitchen who was doing it right. In many cases, the judge would join Gus and Eric in simulating their sexual encounters laughing and joking the entire time.

As trivial and childish as this behavior might seem to some, the importance of posturing a certain sexual identity for Mexican men in the kitchens I studied was central to respect and camaraderie. For instance, one day as Tomas and I sat alone eating dinner before a wave of customers was ready to order we informally spoke of significant others. As we took turns showing pictures of our partners on our cell phones, we seemed to share an appreciation and respect for our significant others. On his break, Tito joined us as we shared photos and I noticed a sharp change in Tomas's relationship talk. Suddenly, he was solely focused on his sexual conquests.

I tell you. This girl here, is wild. Trust me. We met at the other restaurant I used to work at. She is like an assistant to the manager. This one is a wild one. She's going to kill me.

As Tito gave his approval, I could sense Tomas was embarrassed by his abrupt change in discussion as he quickly finished his meal and attended to a table of restaurant patrons. 
While the sexual objectification of female patrons of the restaurant was common, actual interactions with women was something that almost never happened in my two years at the restaurants. At Christmas and New Year's parties and soccer games after closing, there were hardly ever any women present. Much of this can be explained by the legal and language barriers associated with the immigration status of most of the restaurant workers. Frankly, most of the servers at the restaurants I worked at were either on an expired visa or traveled to the United States the undocumented route. As these hard working individuals hide in plain sight as they serve food in restaurants, their opportunities to meet people and maintain relationships is severely restricted. Many servers rely on broken English and learned phrases to communicate with restaurant patrons.

Outside of the restaurant, the staff spends most of their time at home with each other. As Pablo told me, "every time I go out, to the store, to church, to play soccer, I have to be on guard. If I get caught by the police, they will send me back to Mexico." Living in constant fear of repatriation and unable to form relationships outside of the restaurant, the men in these restaurant kitchens spend most of their free time fetishizing women and sharing stories of sexual conquests, which are in reality fantasies. From accounts of partying with a group of sorority girls from the local university to a spontaneous rendezvous with a neighbor, the men in restaurant kitchens often pass the time exchanging stories of sexual conquest. With little opportunity to interact with women, restaurant staff seeks to maximize their opportunities.

During my time in the field, I was shocked by the length they are willing to go. Servers frequently used credit card receipts to find the names of restaurant patrons and 
sought them out on social media sights. During my two years in these kitchens, this never developed into a relationship or a legal issue. Frequently, restaurant servers would catcall or publically discuss women in the restaurant, who due to a lack of Spanish knowledge were unaware of the flirtation and lewd sexual remarks. Quinn (2002), has argued that this sort of public "girl watching" and overt displays of sexuality may be aimed at women, but their main purpose is to build shared masculine identities and social relations.

Scholars of gender make clear the importance of context in the social construction of gender norms and ideologies. In the case of the almost exclusively male populated kitchens in this project, gender norms have shifted. Many scholars point to the traditional, and more specific, homophobic nature of Mexican masculinity. Interestingly, these manifestations of traditional gender ideologies often occur in spaces where men and women intermingle and co-construct gendered behaviors. Gender norms in restaurant kitchens in this study are quite different. During a New Year's Eve party sponsored by the restaurant owner, this became abundantly clear. I arrived at the party at approximately 9PM. Tired after a long day of work, the restaurant staff sat together drinking beer at a large table next to the booth where a local DJ, and friend of the owner of the restaurant set up his equipment. Well aware of the unlikelihood of such an occurrence, Chapo commented to his peers, "I hope some ladies come tonight. I'm ready to take one home." As his peers joined in with him and shared hopes of groups of women coming to the party, the restaurant filled with more and more men; friends and workers of other Mexican restaurants in town. 
By 11:00 when I decided to count the number of men and women in the restaurant, there were 37 men and four women at the party. Lacking women to dance with, the men improvised. At first, men would jokingly run up behind another man and dance behind him, onlookers laughing at the mockery. Later, the frequency of same sex dancers increased and the dance floor was filled with men dancing with other men. Pena (1991), found that men participating in these charritas coloradas (red jokes) where behaviors were half joking, half serious were based in aggressive male posturing. Posturing aimed at achieving symbolic dominance over other men. Shocked by this phenomenon, I asked Tomas what was happening. Without hesitation or a hint of jest, Tomas exclaimed, "there is no women so sometimes we have to dance with each other." As the night wore on and the restaurant staff consumed more and more alcohol, the dance floor remained busy. Men dry humped the floor, chairs, each other, and in one case, a microphone.

While everyone laughed, not one person objected to the emergent gender norm. Indeed, the need to construct new ways of defining masculinity and real men was a pressing matter for restaurant workers. In addition to public discussions of sex and sexuality and hyper competition among servers, claims of authentic masculinity hovered on the theme of material goods. Lacking the legal means to buy large houses, fancy jewelry, and in possession of relatively large amounts of income, many restaurant workers used cars to express their masculinity.

\section{Real Men and Market Masculinity}

The value of possessing material forms of wealth to display was a central theme of authentic masculinity claims in restaurant kitchens. In many ways, the material wealth 
displays (i.e. cars, clothing, shoes, etc.) were public validations of hard work and financial independence. For many of the restaurant workers who traveled through inhospitable terrain to search for employment and meager wages, the ability to send remittances to family back home in Mexico and to be financial secure enough to make larger purchases granted individuals a status many newcomer immigrants in the kitchens modeled as their ideal. Despite the status granted to workers who consume material culture, there are a series of institutional barriers which limit the options of the often undocumented restaurant staff.

It was a rainy Tuesday evening and the restaurant was only sparsely full. Sitting at the bar, the workers perused car advertisements, ranking each car and commenting on what seemed to be an always too high asking price. Eric, the head cook, emerges from the kitchen and tells the owner they have run out of tomato sauce. This shortage is common in the restaurant and indeed part of the normal routine of the restaurant. Typically, a server is told to walk to a nearby grocery store to buy the tomato sauce. On this rainy evening, nobody wanted to walk. Finally, Freddie, a 15 year old local high school student with a fake license volunteers to buy the tomato sauce. As he gets in his old dilapidated minivan and leaves, the servers share with me that none of them have driver's licenses, and that Freddie was the only one had one, albeit it was a forgery. They envied Freddie for this. Having a fake driver's license provided Freddie with status in the restaurant where car culture was a major theme of discussion and debate; where most breaks were spent under the hood of a car, sharing mix-tapes and showing off new car sound systems, and using the restaurant hose to wash cars. 
The restaurant staff owned a myriad of older and often poor functioning cars, trucks, and SUV's. All of their cars were purchased in cash and none were registered with the Department of Motor Vehicles. It was common for cars to break down on the way to the restaurant and for cars to spend weeks at a time parked in the parking lot of the restaurant due to mechanical issues. During slow periods and break at the restaurant the kitchen staff would smoke cigarettes and work on the cars. Chucho, a recent undocumented immigrant working at the restaurant boasted one day of the purchase of his 2004 Dodge Durango. He had traveled nearly two hours to Kansas City to buy the car from a car salesman in the Mexican community of the larger metro area. "How did you get it here?" asked Rico. "Don't be jealous, man. The engine is strong. I drove it here on the highway going 80mph the whole time," responded Chucho.

The group of restaurant staff laughed at the exchange, but perhaps most importantly, recognized that Chucho having a car meant they needed to treat him differently. A few months before when he was new to the restaurant, Chucho was talked down to, tricked regularly, and left out of group gatherings. Now that he had an SUV, and that many of the workers did not have a car or any form of steady transportation, they became dependent on him for transportation to and from work and to social activities. His social capital and claims of authentic manhood were quickly crystallized and his position in the kitchen is now that of a leader, often degrading and mocking others in the kitchen. Indeed, to own a car in the restaurant kitchen is to have the power to control other workers, to impose your will, and to make your claim as the leader of the group. The type of car did matter, however. Chucho's 2004 Dodge Durango was in many ways a status symbol and marker of material masculinity, but his SUV was in 
competition with a slew of others for most prized possession among the kitchen staff.

Gabriel, a young Mexican immigrant worked at the restaurant on weekends as well as at a local home remodeling company during the week. He was 19 years old and did not have a family back home in Mexico and was thus looked down upon by the other restaurant workers who were here with the sole purpose of earning enough money to one day return to Mexico with a financially stable family. "He's just here for fun," Chapo told me one day as Gabriel showed off his new iPhone across the kitchen. When I asked what he meant by this, Chapo said:

"He's dumb for spending all his money like that. I have a family back home. They are the reason I am here right now. I don't drink. I don't party. I use the bike to get here. Because I am saving my money. When I go back to Mexico, I'm going to be able to buy a farm. Chickens, goats, pigs, everything. My wife and our three boys are going to be able to live like I couldn't when I was growing up. What is he [Gabriel] going to have when he leaves. That phone won't work in Mexico.

To my knowledge, I was the only person who Chapo shared these feelings with. Even though after a series of conversations I got a sense that this feeling was shared by many of the restaurant staff, Gabriel still commanded and received serious respect. His relatively new 2013 Chrysler 500 was by far the most expensive car any of the servers owned. Jealousy of his material possessions was obvious, particularly because Gabriel, unlike most of the others, frequently had a girlfriend. When I asked him about this, he told me, "I am young, handsome, and rich. That's what the women want these days. You can be as nice as you want or dance as good as Michael Jackson, but the most important thing is to look nice and have nice things. My car says a lot about me. Once I get them in there, it's over. My work is done." Having the car was not only a marker of manhood and status in the kitchen, but also in the small community of Mexican immigrants and their families. 
Of all the cars and car owners, though, Carlos, the owner of Paisanos possessed

the most respect and status for his brand new 2014 Ford F-250, fully customized with

twenty inch rims and a metal mold of a bull's scrotum dangling from the hitch.

Commenting to me about the truck, Hugo said:

When I opened this restaurant, I told my wife [Hugo does not have a wife. His long time girlfriend and mother of his three children has repeatedly refused to marry Hugo; a topic of much discussion and shame for Hugo who still refers to her as his wife] I deserved to get this truck. I worked very hard to put all this together and I wanted to reward myself. To be honest, though, I think I have made a mistake. Yeah, the truck looks nice, but I when I fill it up with gas, it costs almost $\$ 75$ each time. And I have to fill it up two or three times a week...then I spent too much on the rims. I thought it was a good deal, $\$ 500$ for the rims, but I didn't know the tires would cost $\$ 500$ more and then when I took it to the mechanic and asked them to put it on, they told me they needed to redo the alignment to make it fit. It cost me almost \$2000. Live and learn, my friend.

Carlos consistently parks his truck in the "NO PARKING" zone in front of the large front window of the restaurant. Constantly on display to restaurant patrons and staff, many conversations at the restaurant were based on the large truck. On rare occasions, Carlos would let a server drive his truck to the nearby grocery store to pick up an item. Servers would fight over the opportunity to do so, the winner usually the one willing to do an extra task such as clean the bathroom or wipe the bar down. When I asked him if he was worried they might crash his truck, Carlos responded, "No way, my friend. They know who I am. They are going to take it very careful with my truck. Or else, they know what will happen." I did not know what would happen, and fortunate for everyone involved, we never found out.

\section{Conclusion}

Clearly, a workplace such as a restaurant kitchen is a site for the production and negotiation of masculinity. The fact that so many Mexican immigrant men work in 
Mexican restaurant kitchens as cooks and servers that it has become an almost exclusively male dominated niche of the immigrant labor market makes it an important social world to study interactions if we are to better understand what variables contribute to claims and challenges of authentic manhood and in how these claims connect to a more broad discourse on authenticity in immigrant communities. Two years of fieldwork and interactions with restaurant staff has revealed that masculinity in the restaurants in this study was highly fluid. In some instances, real men provided nuclear and extended families with money, in others, the mode of transportation they used measured their manhood, and perhaps the most central theme, real men publically discussed and demonstrated their sexual prowess.

In the case of this community of restaurant workers, a severe lack of female coworkers and acquaintances produced a series of homosocial behavior where traditional gender norms guided by homophobic ideologies were replaced by new contextually socially acceptable displays of masculinity such as men dancing with men, men caressing other men, and men competing to be recognized as the better cook. From these findings, we must recognize that masculinity is directly related to an individual's structural location. For the Mexican restaurant staff with little to no contact with the surrounding community, and often without legal documentation to live or work in the United States, we see that masculinity develops with tensions of racist Nativism and fears of repatriation in the backdrop. From within these structural barriers, the restaurant staff has developed a new form of authentic manhood and masculinity, not transferable to other contexts, but dominant in the kitchens they find themselves in. 


\section{REFERENCES}

Anderson, Elijah. 1999. Code of the Street. Norton Press.

Berger, Peter and Thomas Luckmann. 1967. The Social Construction of Reality: A Treatise in the Sociology of Knowledge. Anchor Books.

Bourdieu, Pierre. 1984. Distinction: A Social Critique of the Judgement of Taste. Translated by Richard Nice. Cambridge, MA: Harvard University Press.

Brubaker, R., et al. 2007. Nationalist Politics and Everyday Ethnicity in a Transylvanian Town. Princeton, NJ: Princeton University Press.

Burke, P.J. 1980. The Self: Measurement Implications From a Symbolic Interactionist Perspective.” Social Psychology Quarterly, 43: 18-29.

Blumer, Herbert. 1986. Symbolic Interactionism: Perspective and Method. University of California Press.

Christ, Stephen. 2015. "Migrant Workers," in Encyclopedia of Family Studies. Wiley $\&$ Sons Press.

Cohen, Trevor. 2011. "One-way Ticket or Circular Flow: Changing Stream of Remittances to Latin America." Council on Hemispheric Affairs.

Cornell, Stephen and Douglas Hartmann. 1998. Ethnicity and Race: Making Identities In a Changing World. Thousand Oaks, CA: Pine Forge Press.

Davis, J. 1991. Who is Black? One Nation's Definition. University Park, PA: Penn State Press.

Espiritu, Y. L. 1992. Asian American Panethnicity: Bridging Institutions and Identities. Philadelphia: Temple University Press.

Gans, H.J. 1979. "Symbolic Ethnicity: The Future of Ethnic Groups and Cultures in America." Ethnic and Racial Studies, 2:120

Goffman, Erving. 1959. The Presentation of Self in Everyday Life. Doubleday.

Gordon, M.M. 1964. Assimilation in American Life: The Role of Race, Religion, and National Origins. New York: Oxford University Press.

Gubrium, Jaber F. and James A. Holstein. 1999. The Self We Live By: Narrative Identity in a Postmodern World. New York: Oxford University Press. 
Gubrium, Jaber F. 1975. Living and Dying at Murray Manor. University of Virginia Press.

Gutierrez, David G. 1995. Walls and Mirrors: Mexican Americans, Mexican Immigrants, and the Politics of Ethnicity. Berkeley, CA: University of California Press.

Jimenez, Tomás R. 2010. “Affiliative Ethnic Identity: A More Elastic Link Between Ethnic Ancestry and Culture" Ethnic and Racial Studies, 33(10): 17561775 .

Kitwana, B. 2005. Why White Kids Love Hip Hop: Wanksters, Wiggers, Wannabes, and the New Reality of Race in America. New York: Basic Civitas Books.

Jimenez, Tomas. 2009. Replenished Ethnicity: Mexican Americans, Immigration, and Identity. Berkeley, CA: University of California Press.

Macias, Thomas. 2004. "Imaginandose Mexicano: The Symbolic Context of Mexican American Ethnicity Beyond the Second Generation." Qualitative Sociology 27(3) 199-315.

Mead, George Herbert. 1967. Mind, Self and Society. University of Chicago Press.

Min, Pyong Gap. 2010. Preserving Ethnicity Through Religion in America: $\quad$ Korean Protestants and Indian Hindus Across Generations. New York: New York University Press.

Nagel, Joan. 1997. American Indian Ethnic Renewal: Red Power and the Resurgence of Identity and Culture. New York: Oxford University Press.

Portes, Alejandro and Min Zhou. 1993. "The New Second Generation: Segmented Assimilation and its Variants." The Annals 503:74-96.

Ramirez, Hernan. 2011. "Masculinity in the Workplace: The Case of Mexican Immigrant Gardeners," Men and Masculinities, 14(1): 97-116.

Ramirez, Hernan, and Pierrette Hondagneu-Sotelo (2009), "Mexican Immigrant Gardeners: Entrepreneurs or Exploited Workers?" Social Problems, 56(1): 70-88.

Rose, Nikolas. 1998. Inventing Our Selves. Cambridge University Press.

Sewell, William, Jr. 1992. "A Theory of Structure: Duality, Agency, and Transformation." American Journal of Sociology 98:1-29.

Thomas, W.I., 1923. The Unadjusted Girl. Boston: Little, Brown, and Co. 
Vasquez, Jessica M. 2010. "Blurred Borders for Some But Not "Others:" Racialization, "Flexible Ethnicity," Gender, and Third-Generation Mexican American Identity.” Sociological Perspectives 53(1) 45-72.

Warikoo, N. 2004. "Cosmopolitan Ethnicity: Second Generation Indo-Caribbean Identities," in Becoming New Yorkers: Ethnographies of the new Second Generation. New York: Russel Sage Foundation.

Waters, Mary. 1990. Ethnic Options: Choosing Identities in America. Berkeley: University of California Press.

Wilkins, A. 2008. Wannabes, Goths, and Christians: The Boundaries of Sex, Style, and Status. Chicago: University of Chicago Press.

Yodanis, Carrie., Lauer, Sean., and Ota, Risako. 2012. "Interethnic Romantic Relationships: Enacting Affiliative Ethnic Identities. Journal of Marriage and Family, 74. 5:1021-1037. 


\title{
CHAPTER 4
}

\section{COOKING WHILE BROWN: PENALIZING AUTHENTICITY}

\begin{abstract}
This paper examines the institutionalized bias ethnic restaurant owners and workers perceive and experience during regular county health inspections. Ethnic restaurants are commonly perceived as "dirty" or "unclean" by, typically White, health inspectors who in turn are more likely to record more serious health code violations at these restaurants than they would at an "American" restaurant. In order to properly analyze the relationship between bias in health code inspections in ethnic restaurants, this study incorporates quantitative analysis of public health violation data for ten Missouri counties, as well as qualitative data from participant observations in ethnic restaurants and semi-structured interviews with owners of these restaurants. Special emphasis is placed on the institutionalized construction of racially and ethnically themed restaurants as being dangerous and dirty, and the legal consequences for restaurant owners who must deal with the legal and economic issues resulting from their bias health inspection results.
\end{abstract}

Keywords: Authenticity, Restaurants, Race/Ethnicity, Critical Race Theory

According to recent data gathered by the Centers for Disease Control and Prevention (CDC), foodborne illnesses associated with "ethnic" foods has been increasing steadily in recent years and currently accounts for more than $11 \%$ of all total outbreaks (CDC 2009). Many scholars point to ethnic restaurants specifically for being responsible for such cases (Lynch, Painter, Wooddruff \& Braden 2006; CDC 2011). Jones and Angulo (2006) contend that foodborne illness outbreaks resulting from exposure to pathogens in ethnic restaurants are much higher than in home cooked ethnic cuisine. With ethnic restaurants serving a large client base, exposure to unhealthy pathogens results in the spread of illness on a much larger scale. Of all ethnic restaurant types, researchers have found that Mexican, Italian, and Asian are most commonly associated with such cases of foodborne illness (Kwon, Choi, Liu \& Lee 2012; Simonne, Nille, Evans \& Marshall 2004).

Much research has been devoted to potential organizational flaws which might contribute to the production and consumption of foodborne illnesses. Kwon et. al (2006) 
found that food safety training was severely lacking from management of most ethnic restaurants included in a random sample. Indeed, a recent study conducted on the owners independent ethnic restaurants found that only $26 \%$ of these restaurants provided food safety and handling training to new employees (Ram, Sanghera, Abbas \& Barlow 2000). Additional hurdles to providing food safety training to new employees of ethnic restaurants include time constraints, employee attitudes, and language barriers (Roberts et al. 2008; Mauer et al. 2006).

A longstanding measure of food safety has long been regular, state mandated health code inspections. It is commonly assumed that such health inspections safeguard the community against unhealthy food preparation practices and thus ensure that ethnic restaurants maintain state mandated food storage and preparation safety practices (Kwon 2012; Binkley, Nelson \& Almanza 2008). Seiver and Hatfield (2002) go so far as to claim that public disclosures of restaurant inspection results serve to benefit consumers, and society at large, by increasing awareness of the risks of eating at certain restaurants.

The institutional policy of marking restaurants as health code risks creates serious issues for restaurant owners who must deal with the legal and economic issues resulting from their health inspection results. The power of the state, more specifically, the health inspector to construct an organizational identity is a realm of food studies which calls for much more study. Only a small minority of studies have examined the subjective positions of public safety professionals who conduct such inspections of restaurants. Mauer et al. (2006) found that many public health inspectors were of the opinion that ethnic restaurants were critically underprepared and inadequately working to meet state mandates. Related, a recent comparative analysis of ethnic and non-ethnic restaurants 
found that ethnic restaurants were cited for food code violations (both critical and noncritical) significantly more often per facility than their non-ethnic counterparts (Kwon et al 2006). This leads many scholars of foodways to study role of restaurant staff in producing such violations.

The present study departs from this common trend and places the locus of study on the role of public health inspectors in producing reports of food code violations. This paper combines and examination of the institutional bias ethnic restaurant owners and workers perceive and experience during regular county health inspections. Taking into consideration the predominant stereotype that ethnic restaurants are "dirty" or "unclean" by typically White patrons and health inspectors, this study questions the subjective role of public health inspectors in generating more serious health code violations at ethnic restaurants than they would at an "American" restaurant, and thus, reinforce existing stereotypes. In order to properly analyze the relationship between bias in health code inspections in ethnic restaurants, this study incorporates quantitative analysis of public health violation data from a random sample of ten Missouri counties, as well as qualitative data from participant observations in ethnic restaurants and semi-structured interviews with owners of ethnic restaurants. Special emphasis is placed on the institutional construction of racially and ethnically themed restaurants as being dangerous and dirty, and the legal consequences for restaurant owners who must deal with the legal and economic issues resulting from their bias health inspection results.

\section{A Critical Race Theory Approach}

The United States has historically been a site of racial and ethnic struggle between many groups competing for limited resources. Along these lines of struggle emerged the 
existing racial/ethnic hierarchy which dominates U.S. society and culture. The dominant (economically, culturally, ideologically, etc.) racial group in the U.S. has long been Whites (Almaguer 2008; Shapiro 2005; Lopez 1997). In this sense, Whites have long possessed the power to define the national and racial identity of the nation. It is precisely this power associated with White privilege which critical race scholars interrogate in order to uncover the institutional roots of inequality in U.S. society.

Critical race theory (hereafter CRT) is an arena of social research marked by specific theoretical applications of critical theory examining the intersections and complications of race, power, and law in the United States. Rising above individual micro level interactions, critical race theorists recognize that racism is a deep-seated phenomenon prevalent in many of the macro level structures in the United States. Specifically, the legal/penal system and the educational system are viewed as modern day purveyors of institutionalized racism and marginalization (Bonilla-Silva 2003; Feagin 2001; Lopez 1997; Omi \& Winant 1994).

In the CRT framework, individual or collective forms of overt racism which dominated U.S. culture and history up to the twentieth century are no longer prerequisites for the racialization and marginalization of minority groups. Rather, as a result of a long legacy of White supremacy in the United States, covert forms of institutional racism rooted in the legal, educational, and economic structures of society work to continuously maintain the racial status quo by elevating White Americans at the expense of the many marginalized and racialized minority citizens (Almaguer 2008). Since overt forms of racism are not widely accepted or practiced in the twenty-first century as they have been 
in previous centuries, many Americans, not only White, but of a variety of racial backgrounds believe that the U.S. is now a "post-race" society.

This article will apply critical race theory to analyze the structure of daily interactions that occur between non-White ethnic restaurant staff and White public health inspectors and restaurant patrons in public spaces to determine the extent to which race/ethnicity is a determinant of health inspection and online rating results. This focus on the day to day interactions of non-White ethnics and Whites uses critical race theory as a frame to understand the experiences of individuals with structural and interpersonal discrimination. These microagressions have been well noted to manifest in many everyday activities, but there exists little research on how institutional discrimination affects non-White ethnic restaurant owners (Collins 2005; Williams 1991).

Ethnic Restaurants in the U.S.

Being a nation of immigrants, the United States has always had a wide variety of ethnic food options for consumers. With the expansion of capitalism and consumerism in the early $19^{\text {th }}$ century, ethnic restaurants emerged as a popular food option for ethnic and non-ethnics alike (Mariani 1991). Established by immigrant entrepreneurs and supported by large waves of Asian and Mexican origin immigrants, ethnic food and restaurants became an integral part of American culture and everyday life (Kwon et al 2012; Mariani 1991). This historical trend is maintained in the $21^{\text {st }}$ century. According to the U.S. Census Bureau (2006), Asians and Latino/as own and operate more restaurants and food operations than all other ethnic groups combined. More specifically, two ethnic themed restaurants dominate the market: Chinese and Mexican. In fact, a recent Chinese Restaurant News (2010) publication reported that in the United States there are currently 
twice as many Chinese restaurants as there are McDonalds, the largest fast food chain in the United States and the world.

While ethnic restaurants have experienced an expansion in consumer base, dominant cultural narratives and stigmas drive many assumptions of restaurants. The myth of "Moctezumas Revenge" is one common stereotype found in public discourse which presents Mexican restaurants as "dirty" or "unclean" by predominantly White community members and mainstream society. Moreover, media representations of ethnic restaurants as "roach coaches" or a place where family pets are served are often internalized by media consumers and thus serve to perpetuate myths of risk and uncleanliness.

Despite these stereotypes, researchers find that a myriad of reasons may be responsible for the rapid growth of the industry. Some scholars point to recent increases in immigration rates from Latin America and Asia to the United States to explain this phenomenon. According to this perspective, recent immigrants longing for food and cultural experiences from "back home," drive demand for foods reminscent of their sending country, thus increasing both the importation and popularity of ethnic foods and foodways. More surprising, however, is the perspective that the popularity of ethnic cuisine, particularly Mexican or Chinese, is more of a reflection of the mainstream U.S. consumer base's desire to depart from the generic and to seek out an exotic or foreign experience.

In an era of globalization, goods, services, and peoples are exchanged at rates never before experienced in the history of the world. One must only drive to their local grocery store to be bombarded with advertisements marketing "authentic tortilla chips," 
"real Indian Korma" or their local farmers market for "authentic" local produce. Indeed, in many ways the global exchange of foods and other cultural products has presented rural and urban individuals alike the opportunity to experience ethnic culture and food in the safety of their own community.

Early globalization scholars predicted that such a manifestation of globalization would serve to flatten cultural differenes between politically and geographically divided regions of the world and would usher in an era of global homogenous culture and ideology. In reality, what has emerged is more representative of the capitalist consumer culture where much like clothing, music, and film, foods represent an opportunity to consume an identity in an increasingly generic world. It is here at the intersection of the democratization of culture, consumerism and modern immigration to the United States that the paradox of authenticity emerges (Cobb 2014).

\section{Methods}

The data used for this article were gathered in two ways. First, in order to generate an in depth representation of the perspective of ethnic restaurant owners and staff members, I engaged in a two year ethnographic research project, beginning in May of 2013 and culminating in March of 2015. Semi-structured interviews concerning public health inspections were conducted with owners and managers at 54 restaurants in total, and ethnographic research was collected in 12 restaurants. As a participant observer in these 12 restaurants, I volunteered my labor for access to kitchen operations, staff meetings, and workplace interactions. In many ways, I joined the service staff of these restaurants. I performed the duties of busboy, host, table server, bartender, and cook. My tasks as host, busboy, and table server included seating patrons, taking drink and meal 
orders, explaining dishes, and generally working to please the patrons of the restaurant. As owners and staff at restaurants grew more confident in my abilities to perform tasks, and less concerned with my motives as a researcher in the restaurant, I was gradually granted more responsibilities and authority in the restaurants. This culminated in my responsibility as cook. As a researcher investigating the preparation of "authentic" Mexican food, it was quite shocking to be given the task of cooking food for patrons of the restaurant. Initially, this began with frying chips, blending ingredients for salsa, and culminated with me preparing complex dishes such as chile relleno and enchiladas - the authenticity of which proved fruitful for discussions of what constitutes authenticity among cooks in the restaurants I worked.

Upon entrance to the field I received much resistance from owners and staff of restaurants alike. As an outsider with no credibility in the local restaurant community, I was viewed as suspicious to owners, many of whom continue to avoid me to this day, and as a threat by servers and cooks who felt my presence in the kitchen as a threat to their employment status. Overcoming these barriers proved difficult, but beneficial to the research process. After months, or in some cases, after a year of working at a myriad of restaurants, I was granted access to the intimate community of restaurants. My research on authentic organizational and subjective identities has led me to out of Mexican restaurants and into the homes of the local Mexican immigrant community. Access to private parties at restaurants, religious celebrations at homes, and participation in a local Mexican restaurant soccer league has allowed me in a very real way to examine how authenticity in a Mexican immigrant community is accomplished in a restaurant context 
as well as how the boundaries of authenticity are policed amongst community members in their everyday lives.

My time as an employee and a participant observer totaled approximately 1000 hours. Participant observation was a vital tool for producing a representational description of the social contexts from which ideals of authenticity are produced and reinforced. I worked at least 30 hours at each restaurant which allowed me to conduct research. This auxiliary research was conducted for the purpose of comparison between restaurants. By serving as a participant observer in many different restaurants, I was able to generate common trends in the production process and important distinctions in purposes and visions of restaurants. Once restaurant in particular, Paisanos, served as a reference group for all others.

At Paisanos, I logged over 500 hours of research. In each setting, I made my role as a social researcher investigating authenticity known to owners and service staff. I was conscious of the negative impact openly taking field notes might have on conversations or interactions at the restaurant, so I used a notepad application on my phone to jot notes in the field. Once I got home, I would elaborate and develop a more complete summary of the day in the field. As a result, my phone had a constant presence in my hand. In fact, I developed a reputation in a few of the restaurants as being a "ladies' man" due to assumptions that I was constantly text messaging women - a reputation that proved to be helpful for the field note process and for gaining the trust of restaurant worker.

The second form of data used for this project was health inspection data from restaurants over a 12 month period (June 30, 2013 to June 30, 2014). A total of 366 restaurant inspection reports from 198 restaurants located in a random sample of 10 
Missouri counties were used to identify persistent patterns in reporting of food violations. Of the sample of 366 restaurants, 214 were "American" style food, 73 were Mexican, and 79 were Asian (including Chinese, Japanese, Korean, and Indian restaurants). The specific research objectives of this dimension of the research project was to identify dominant patterns in the frequency and type of health code violations in restaurants based on the style of food served at the restaurant (i.e ethnic and non-ethnic).

Missouri state law mandates that the Department of Health and Senior Services (DHSS) regularly inspect all operations serving food to the general public, including restaurants, bars, grocery stores, and food courts at schools, hospitals, and nursing homes. While public health inspectors regularly inspect all such food establishments, the frequency at which sites are examined is based on the scale of the food operation. For instance, a gas station which sells prepackaged sandwiches or hotdogs would be subject to inspections far less often than large scale restaurants which feature a wide variety of perishable items on their menu. All food operations are inspected at least once per year, and many restaurants are inspected two or three times a year. During inspections, problems are identified and reported to the owners of the facility. These reports, with specific food code violations, are then made public on county and state sponsored websites. Once given an inspection report the restaurant management has a limited time to address the problem before the health inspector returns.

The present study may provide a more complex understanding of how food code violations are generated and in the consequences for such violations for the management of restaurants. With a special emphasis on the subjective role of the public health inspector, and public discourse of ethnic themed restaurants, this study seeks to highlight 
ethnicized dimensions of inequality experienced by the owners and proprietors of ethnic themed restaurants in Anglo dominated spaces in the Midwest Statistical Data Analysis

Prior to conducting statistical analysis, food code violations represented in public health inspection records were coded into categories recognized by the Missouri Department of Health and Human Services (i.e Critical Violations, Non-Critical Violations, Behavior Related Violations, Non-behavior Related Items, and Critical Behavior Related Items). Once categorized into distinct groups descriptive statistics were generated to summarize the data. Frequencies, cross-tabulations, means, and standard deviations of continuous variables (i.e. number of health inspection, number of critical and non-critical violations, and the average number of violations based on restaurant type) were produced to determine if significant differences could be found between restaurant types.

\section{FINDINGS}

\section{The Shifting Dimensions of Power and Discrimination}

The growing prevalence and influence of Mexican restaurants is undeniable. As of May 2014, there are more than 54,000 Mexican restaurants in operation in the United States. These restaurants comprise approximately 8 percent of the total US restaurant landscape. In fact, as of 2014, Mexican restaurants replaced "Hamburger" restaurants such as Burger King, McDonalds, etc. for the third most common type of restaurant in the United States. In both the Midwest and Southwestern Borderlands, Mexican restaurants are almost exclusively owned by ethnic non-White individuals (CHD 2014). In the case of this study, only one restaurant in the Midwest was owned by a White individual and 
none were owned by White individuals in the Borderlands. In this sense, Mexican restaurants have emerged as an ethnicized niche of the labor market in the United States. Many restaurant owners were quick to point this out. Alma, the owner and cook at a large restaurant along the Rio Grande in Texas referred to this phenomenon as a good thing for Mexican entrepreneurs:

All the restaurants here are owned by Mexicanos. If an Anglo tried to come here to Laredo [TX] to sell Mexican food I would not be worried. They would be laughed at. This is our food. It's part of our culture. Yeah, I like to make money, but this restaurant is bigger than that. People come here because they like the food and they like the environment. An Anglo can't do that.

According to Alma, Mexican food is not merely a profit seeking venture. Restaurants serve as public displays of Mexican culture and identity. In this case, in order to be deemed as a legitimate, and perhaps more directly, an "authentic" Mexican restaurant, the owner of the establishment needed to be Mexican as well. While perhaps some patrons of Mexican restaurants would deem this as a shallow interpretation of Mexican cuisine and culture, the reality of such public discourse is that in places with heavy Mexican populations, the power to define authentic culture and foodways rests in the hands of the ethnic community. Jorge, the owner of multiple restaurants in both the Southwestern Borderlands and Midwest drew a similar comparison:

Before I opened this restaurant in Missouri, I was in the restaurant business in California for 15 years...It's really different over there. You have to really make good food in order to be welcomed into the community. I knew a lot of people who tried to make it, with food trucks and whatnot, but Mexican people don't want to buy that. They want to buy food from someone who looks like their abuela (grandmother). It's hard to say, but it's the truth.

Jorge's comments summarize many of the key foundations to a successful Mexican restaurant shared with me by owners. Particularly in the Southwestern 
Borderlands where ethnic individuals possess more civic and social capital, the salience of ethnicity, and more specifically, Mexican ancestry emerged time and time again in discussions of the status of individual restaurants in the surrounding community. The privileging of Mexican prepared dishes in Mexican owned restaurants reflects larger tensions between racial and ethnic communities in the United States. Speaking of this tension, Alberto, the owner of a small Mexican restaurant in Brownsville, TX explained: Look, I'm going to be honest with you. In Brownsville, there are two types of people. Mexicans, and people who want to deport us to Mexico. It's that simple. Every day you seen the Border Patrol looking for illegals, giving people a hard time, making trouble at schools. In Brownsville, White and Brown don't mix. They do their thing, we stick to our own.

In the border city of Brownsville and many others in the Southwestern Borderlands, tensions still run high. The issue of mass deportation and racial profiling frames much of the public discourse and results in social and residential segregation. In places such as Brownsville where ethnic minorities vastly outnumber non-ethnic Whites, discrimination in economic opportunity or treatment by customers was not reported as a major concern in any of the restaurants whose owner I spoke with. The community of restaurant owners and patrons shared common meanings and experiences. Scholars of ethnic community formation and maintenance point to the role of food in constructing such shared meanings and social worlds. Food has a central role in this process as many significant interactions are based on the sharing of a meal (Pilcher 2012). Mothers and fathers feeding children, office potlucks, community picnics, and religious ceremonies where the Eucharist (bread and wine) have the specific function of bringing together a community and connecting humans to the Divine. As such, food is an important determinant in not only how people see themselves, but also in how people differentiate themselves from others. 
Shifting contexts to the Midwest where Mexican communities are significantly outnumbered by non-ethnic Whites, the issue of discrimination and privilege flips and the power to define communities, cultural legitimacy, and authenticity rests in the White mainstream. Much public discourse in the United States aims to demonize Mexican immigrants in the United States. Fears of unsecured borders, job loss, and criminal syndicates drive anti-immigration propaganda. Over time this message has been internalized by many mainstream Americans who reject Mexican immigration to the United States. One manifestation of this rejection is through the marking of Mexican communities, restaurants, and food as dirty, undesirable, and dangerous. The boundaries we use to define and police our communities, thus, are directly related to the types of foods we eat. Many of these boundaries which influence our world outlook emerge from non-empirically validated falsehoods. For instance, many parents avoid trick-or-treating for fear of poisoned candy, others avoid night activities out of concern that most crime happens after dark. While both of these dominant cultural myths lack empirical validation, the reality of implications and consequences frames behavior options and choices. Once such example of this can be found in a review on the commonly used review website "Yelp." Reviewing the meal received at a Mexican restaurant in the central Missouri area, one restaurant patron wrote the following:

Haven't been back to this place in awhile. I use to go to the restaurant maybe once every couple of weeks. It was just a step up from Taco Bell quality-wise really but I liked their chimichangas so I ordered for take out whenever I did go. One night I ordered a chimichanga and got it home. It came with some rice and tomatoes, etc. on the side as usual. I took a spoonful and as I bit down, I felt something hard and flat and thought it was a burn chip or something at first. Turns out it was a razor blade. Needless to say, I was freaked out. I immediately took the food back and showed the person at the register who didn't know English and didn't seem overly concerned at all. Then they asked if I wanted another one to which I replied NO and give me my money back, please! I then went home 
and wrote a long e-mail to the Columbia health department...I didn't know if someone had maliciously put the blade there or not...the point was it was in my MOUTH and I could have been seriously hurt! (Review posted 12/8/2012)

While indeed a scary description of events, the validity of this story is questionable. Interviews with restaurant owners and management of the establishment mentioned in this review yielded no knowledge of the aforementioned event. Public health inspections and reports as well as local news sources are also lacking any acknowledgement or mention of a sanction for such an event. Such a review can be tremendously consequential for restaurant profitability as the reputation of a public serving organization such as a restaurant relies heavily on the social capital earned through good service, good food, and clean environments. To challenge any of these statuses is to challenge the very core of the restaurant. Similar myths of danger have been perpetuated over the years as Mexican food gained popularity in mainstream American society. In the early $20^{\text {th }}$ century, the term "chili queens" came to define the group of Mexican migrant women who cooked and sold chili from vending booths in the San Antonio, TX downtown square.

As Pilcher (2012) explains, a series of stereotypes emerged of the community of women selling chili, and even the chili itself. On one hand, the foods were seen as alluring. On another, they were seen as dangerous. Much like the jalapeno, the flavor might be quite tasty, but it might burn you. That danger was also transferred from the foods, to the women who served them. The stereotype of the "Hot Tamale" or "Dangerous Mexican Woman" became entrenched within the local food culture. Indeed, the danger of a single story is that it can form a web of social meanings which others can attach to and perpetuate. 
As such, restaurant reviews are tremendously important to the profitability of Mexican restaurants. Almost none of the restaurants in this study allocated funds or efforts of any kind to advertisements. In many cases, word-of-mouth was the singular way restaurants sought to attract a larger consumer base. A quick review of online reviews demonstrates the many subjective definitions of authentic Mexican food, proper and timely service, and reasonable prices. Although subjective and based in individual experiences, restaurant owners were well aware of their online ratings and used such feedback to modify their presentation of food. David, the owner of a large Mexican restaurant overlooking a small lake located in the wealthy part of town shares this attentiveness.

I check online every day. All of them. Google, Bing, Yelp, Trip Advisor, even Facebook. If my customer is talking about us, I want to know what they are saying. If they complain about dirt or bad food, I tell my workers to do better. I want to please the customer, so I need to listen to them.

Reviews are not always helpful for restaurant management. Many revert back to problematic and damaging stereotypes of Mexican immigrants as being lazy, suspicious, and unwilling to speak or learn English. A review of David's restaurant yielded the following review.

Awful service and people do not speak English! I could not understand the waiter at all. (Review posted 11/10/2011)

In an interview when read this review, David appeared flustered. "This is just not true," he exclaimed. Most of my servers are not Mexican. They are White, or Black, whatever. College students. I have a couple servers who are Mexican but they speak English very good." David was visibly upset by this review. Although it seemed he was trying to downplay its significance, he later commented that this is something is deals with 
frequently. "When the food guy comes [bulk food distributor], I can't deal with him. I tell my manager to do it. At first I did it, but he is racist. He plays dumb with me. I try to talk to him like a man, but he treats me like I'm below him." Managers like David are in a difficult position. As public displays of ethnic and cultural identities, restaurants are frequently marked as different, othered by both restaurant patrons and community members. This is to say, Mexican restaurants in the United States symbolize the boundary between private cultural and ethnic customs and communities, and public American practices (Lu and Fine 1995). As such, online reviews frequently cited stereotypical tropes of Mexican immigrants. For instance, in the following review of a small Mexican restaurant almost exclusively frequented by the local Mexican community, the reviewer chose to focus on fears of suspicious and dirty service staff.

Heed this warning: if you want mouth breather based service in conjunction to bland food. This place is for you. If I didn't make eye contact with my waste of space waiter after he looked up from taking an Instagram "selfie" I probably would have left. I actually kind of regret not leaving after he drooled on his own arm during my order. Then the food came out. Covered in garnish. I mean covered. Like they were hiding something. (Review posted 4/24/2013)

Dominant stereotypes continue to frame the Mexican immigrant experience in the United States. In places where immigrants share or compose a large proportion of the ethnic/racial demographic composition, restaurant owners and management were much less likely to report instances of perceived racial or ethnic discrimination. As a manifestation of long term settlement along the Borderlands, Mexican communities have gained the social capital to police the boundaries of their own communities, and in many ways, control the image and perception of the food landscape. In regions of the United States were Mexican migration is a contemporary development, such as the Midwest or Southeast, Mexican communities are marked as others, relegated to the periphery, and 
defined by dominant mainstream cultural stereotypes. In order to understand the potential implications of such socially constructed identities, the second phase of this project was to analyze public health inspection records.

\section{The Effect of an Ethnic Status on Health Inspections}

A major focus of this study concerns the effect of ethnic restaurant status on public opinion, and more specifically, public health inspection reports. Excluding Asians, minorities in the United States experience lower rates of employment, lower family incomes, and higher incarceration rates (Sohoni 2014; Duran 2008; Pager 2003). The degree to which this is a manifestation of racial formations is increasingly contested in a color-blind society (Bonilla-Silva 2011). In such a cultural climate, the ideology of not believing that race is still an issue as a result of a decrease in overt racist behavior, such as the $\mathrm{KKK}$, is what perpetuates and overlooks the institutional discrimination minorities experience in the United States. This study is uniquely suited to address both the issue of perceived discrimination and quantifiable evidence of state agencies and their reporting practices in ethnic and non-ethnic restaurants. Whereas subjective perceptions and constructions of ethnic restaurants are obviously biased, public health inspection results offer the unique opportunity to examine a seemingly unbiased representation of the Mexican entrepreneurial experience.

Figure 1 presents the percentage of ethnic and non-ethnic restaurants in the sample of ten Missouri counties. The gap in frequency of ethnic and non ethnic restaurants is significant. Of the sample of 366 restaurants, 214 were "American" style food, 73 were Mexican, and 79 were Asian (including Chinese, Japanese, Korean, and Indian restaurants). 


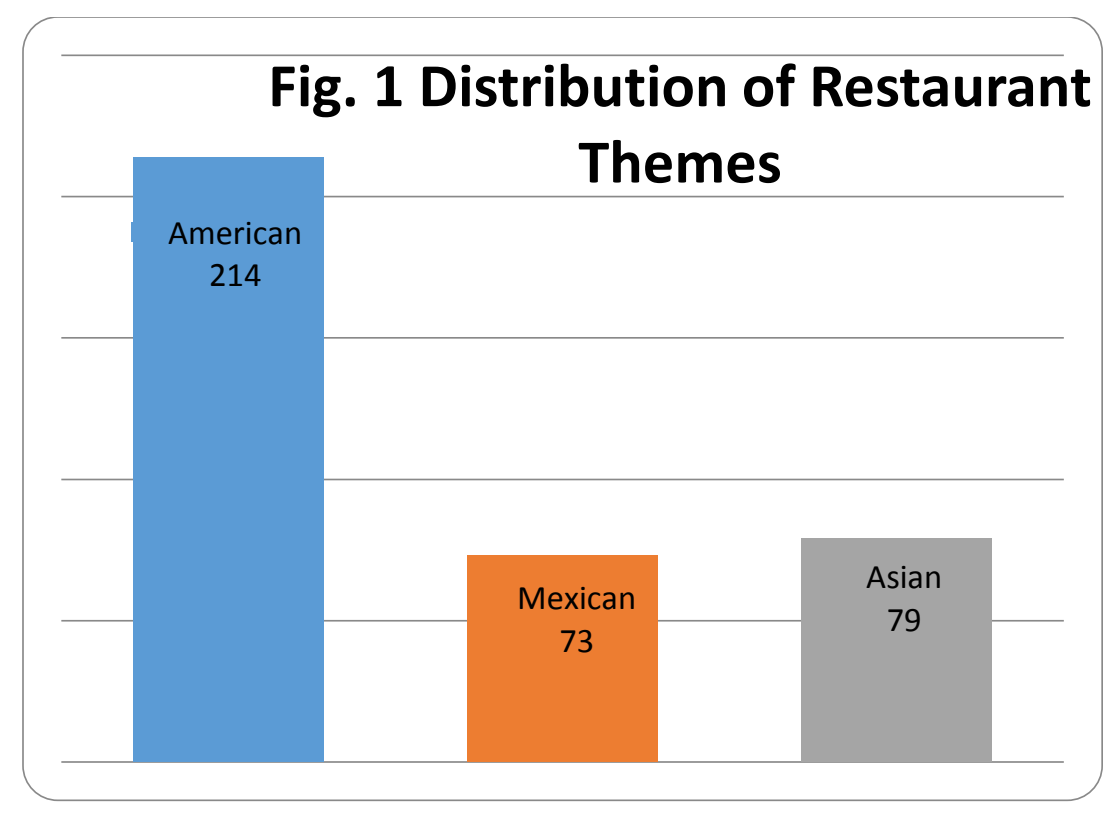

A total of 484 restaurant inspection reports from 366 restaurants were used to identify any persistent patterns in reporting of food violations. Figure 2 presents the average health inspection score of ethnic and non-ethnic restaurants.

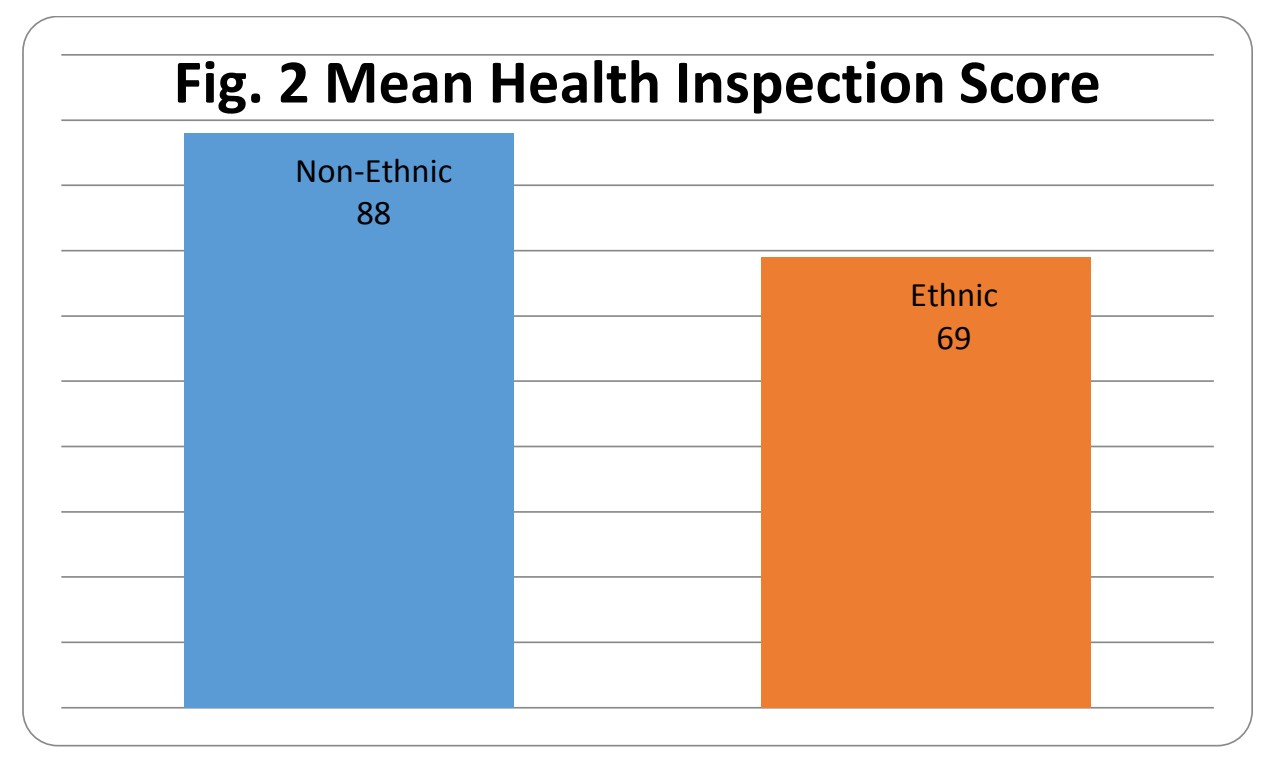

Among non-ethnic or "American style restaurants, the average health inspection score was 88 while the average ethnic restaurant health inspection score was 69 . Figure 3 is a more detailed breakdown of the mean public health inspection score. This table 
distinguishes the "ethnic" designation into Mexican and Chinese. As illustrated in the table, both Mexican and Chinese restaurants are scored significantly lower by public health inspectors. In the case of the ten random Missouri counties in this study, Chinese restaurants may face more stigmas than Mexican restaurants.

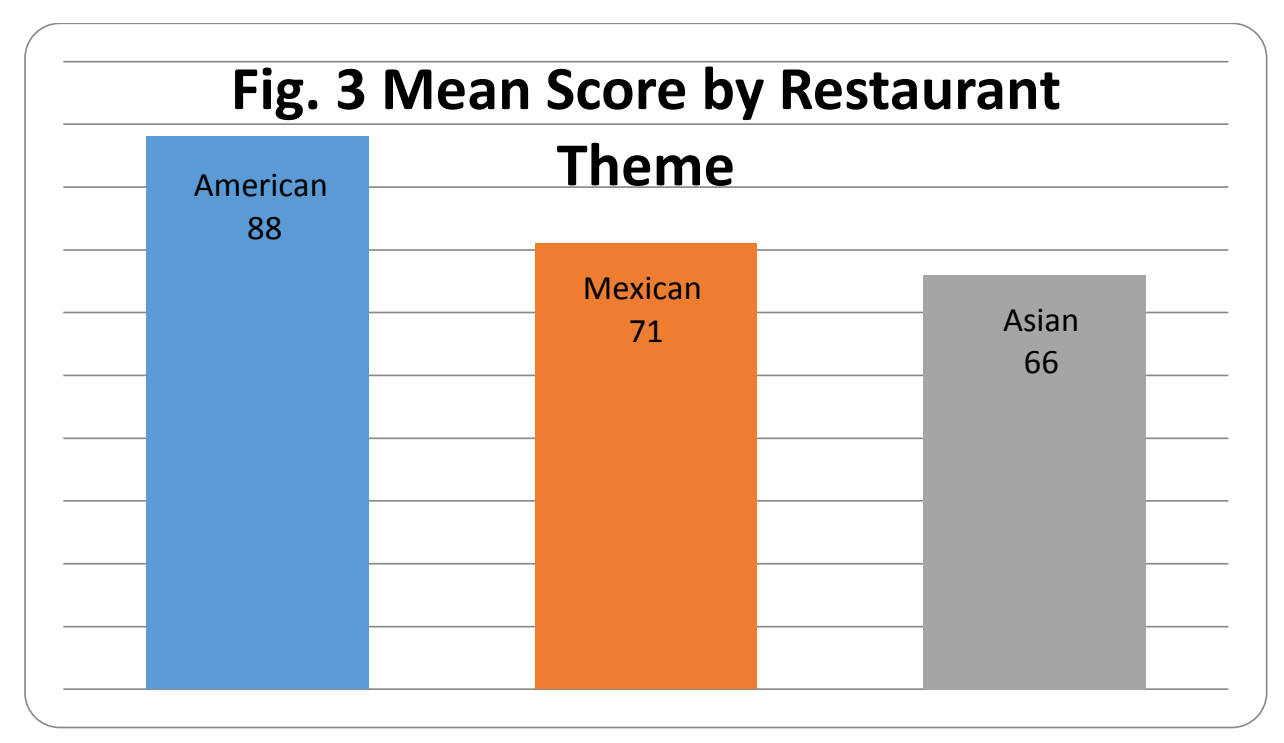

The degree of influence in public health inspection reports which ethnicity contributes is revealing of larger and more systemic racial and ethnic concerns in the United States. While previous research has cited a lack of employee training and traditional means of preparing food as the main variables in health inspection results, the findings of this study suggest that public discourse and stereotypes of immigrants communities, and more specifically, food and restaurants, continue to impede the social integration and economic development of immigrant communities in the Midwestern United States. The degree to which ethnicity is perceived to be a barrier to integration by restaurant owners and staff members is validated by the skewed health inspection records of such restaurants. 


\section{Conclusion}

In many ways, the experiences of owners and staff of ethnic restaurants represent ongoing tensions between racial and ethnic groups in the United States. The research reported here in this article connects to the color-blind ideology which frames public discourse and interactions. Power, both on an individual and community level functioned to establish the norms and values of the community. In the case of Mexican restaurant owners and staff in the Southwestern Borderlands, power was with within the ethnic community. As such, restaurant management consistently reported a sense of authority in the community, control over the operations of the restaurant, and as pillars in the community.

Additionally, Borderlands restauranteurs expressed opinions of widespread marginalization of non-ethnic entrepreneurs seeking to establish a Mexican restaurant in their community. In both theory and practice, the communities of the Southwestern Borderlands actively policed the boundaries of acceptable Mexican food. While the authenticity of the specific meals were never directly addressed, the assumption and prejudice which dictated that only ethnic Mexicans could operate a successful Mexican restaurant served to marginalize outsiders and maintained control of the Mexican restaurant market within the community itself. Outside the Southwestern Borderlands in the Midwestern United States, the power of the ethnic community was almost completely the opposite. Whereas Mexican communities were well established and highly proportional to the entire population, Midwestern ethnic communities, both in the case of Mexican and Asian, were significantly in the minority. 
Paradoxically, as business boomed for these ethnic restaurants, perceptions by both restaurant owners and staff consistently yielded sensitivities towards perceived discrimination from both the community at large as well as in public health inspections mandated by the state department of health. Analysis of these public health inspection reports found that there is indeed a difference within both the frequency of which health code violations are reported in restaurant inspections and in the mean inspection score for ethnic and non-ethnic restaurants. As illustrated in this paper, non-ethnic restaurants consistently experienced fewer violations and enjoyed higher inspection scores.

A bevvy of research has emerged on the restaurant industry as it relates to the growing problem of foodborne illnesses. Much of this research has pointed to the restaurant industry, and more specifically, the ethnic restaurant industry to account for such trends. Many scholars point to poor training practices, insufficient knowledge or desire to perform safe food handling, and language barriers as explanations of health code violations. While not to dismiss the severity or risk associated with improperly handling or preparing food, this paper suggests that institutional level discrimination directly relates to more health code violations and economic ramifications in ethnic restaurants. In particular, dominant cultural narratives of ethnic restaurants being dangerous, dirty, or beneath the standards of American restaurants contribute to a climate of labeling ethnic restaurants and communities in Anglo dominated spaces as different. As demonstrated in this paper, this othering process leads to significant issues for ethnic restaurateurs who must deal with prejudice in public discourse and health inspections as much as the dayto-day stresses related to preparing meals to please a growing consumer base which 
simultaneously seeks the ethnic cuisine out while marking ethnic communities and cuisine as inferior and perpetuating the myth of harmful immigrant ethnic communities. 


\section{REFERENCES}

Alba, Richard and Victor Nee. 2003. Remaking the American Mainstream: Assimilation and Contemporary Immigration. Cambridge: Harvard University Press.

Almaguer, Tomas. 2008. Racial Fault Lines: The Historical Origins of White

Supremacy in California. $2^{\text {nd }}$ ed. Berkely, CA: University of California Press.

Bhabha, Homi. 1994. The Location of Culture. Routledge.

Bonilla-Silva, Eduardo. 2011. Racism without Racists: Color-Blind Racism and the Persistence of Racial Inequality in the United States. Oxford: Roman \& Littlefield Publishers.

Centers for Disease Control and Prevention. 2009. Preliminary FoodNet Data on the Incidence of Infection With Pathogens Transmitted Commonly Through Food-10 States, 2007.

Centers for Disease Control and Prevention. 2011. Surveillance For Foodborne Disease Outbreaks--United States, 2008. Morbidity and Mortality Weekly Report, 60, 1197-1202.

Chinese Restaurant News. 2010. Chinese Restaurants in USA Dining Guide.

Collina, Patricia H. 2005. Black Sexual Politics: African Americans, Gender, and the New Racism. New York: Routledge.

Feagin, Joe R. 2001. Racist America: Roots, Current Realities and Future Reparations. New York: Routledge.

Golash-Boza, Tanya. 2006. "Dropping the Hyphen? Becoming Latino(a)-American through Racialized Assimilation." Social Forces 85(1).

Gomez, Laura. 2007. Manifest Destinies: The Making of the Mexican American Race. New York: NYU Press.

Jones, T. F. \& Angulo, F. J. (2006). "Eating In Restaurants: A Risk Factor For Foodborne Disease?" Clinical Infectious Diseases, 43, 1324-1328.

Kwon, J., Young Gin Choi, Pei Liu, \& Yee Ming Lee. 2012. "Food Safety Training Needs For Asian Restaurants: Review of Multiple Health Inspection Data In Kansas." Journal of Foodservice Management \& Education, 6, 10-15. 
Kwon, J., Roberts, K., Shanklin, C. W., Liu, P., \& Yen, W. S. 2009. "Food Safety Training Needs Assessment For Independent Ethnic Restaurants: Review of Health Inspection Data in Kansas." Food Protection Trends, 30, 412-421.

Kwon, J., Wilson, A. S., Bednar, C. M., \& Kennon, L. 2008. "Food Safety Knowledge and Behaviors of Women, Infant, and Children (WIC) Program

Participants in the United States.” Journal of Food Protection, 71, 1651-1658.

Lichter, Danitl T. et al., 2007. National Estimates of Racial Segregation in Rural and Small-Town America. Demography 44(3) 563-81.

Lichter, Daniel T. 2009. Immigrant Gateways and Hispanic Migration to New Destinations. International Migration Review 43(3) 496-518.

Lichter, Daniel T., Domenico Parisi, Steven Michael Grice, and Michael Taquino. 2007. "Racial Segregation in Rural and Small Town America: Does New York State Fit the National Pattern?" Community and Rural Development Institute Research and Policy Brief Series 10.

Lopez, Ian H. 1997. White by Law. New York: NYU Press.

Lynch, M., Painter, J., Woodruff, R., \& Braden, C. 2006. Surveillance For Foodborne Disease Outbreaks--United States, 1998-2002. Morbidity and Mortality Weekly Report, 55,1-34.

Massey, Douglas. 2002. Beyond Smoke and Mirrors: Mexican Immigration in an Era of Economic Integration. Russell Sage.

Mauer, W. A., Kaneene, J. B., DeArman, V. T., Roberts, C. A., Miller. R., Pong, L., \& Dickey, T. E. 2006. "Ethnic-food Safety Concerns: An Online Survey of Food Safety Professionals." Journal of Environmental Health, $\quad 68(10), 32-38$.

Omi, Michael and Howard Winant. 1994. Racial Formation in the United States. New York, NY: Routledge Press.

Portes, Alejandro and Ruben G. Rumbaut. 2001. Legacies: The Story of the Immigrant Second Generation. Berkely, CA: University of California Press.

Portes, Alejandro and Ruben Rumbaut. 1990. Immigrant America: A Portrait. Berkeley, CA: University of California Press.

Ram, M., Sanghera, B., Abbas, T., \& Barlow, G. 2000. "Training and Ethnic Minority Firms: The Case of the Independent Restaurant Sector." Education and Training, 42, 334-341. 
Roberts, K. R., Kwon, J., Shanklin, C. W., Liu, P., \& Yen, W. S. F. 2011. "Food Safety Practices Lacking in Independent Ethnic Restaurants." Journal of Culinary Science and Technology, 9, 1-16.

Roberts, K., Barrett, B., Howells, A., Shanklin, C., Pilling, V. K., \& Brannon, L. A. 2008. "Food Safety Training and Foodservice Employees Knowledge and Behavior." Food Protection Trends, 28, 252-260.

Rodriguez Dominguez, Victor M. 2005. “The Racialization of Mexican Americans and Puerto Ricans." Centro Journal 17(1) 71-105.

Roediger. David R. 1991. The Wages of Whiteness: Race and the Making of the American Working Class (Revised Edition). Verso: London.

Seiver, O. H., \& Hatfield, T. H. 2002. "Grading Systems For Retail Food Facilities: Preference Reversals of Environmental Health Professionals." Journal of Environmental Health, 64(10), 8-13.

Simonne, A. H., Nille, A., Evans, K., \& Marshall, M. R. 2004. "Ethnic Food Safety Trends In the United States Based on CDC Foodborne Illness Data." Food Protection Trends, 24, 590-604.

Telles, Edward and Vilma Ortiz. 2009. Generations of Exclusion: Mexican Americans, Assimilation, and Race. New York: Russell Sage Foundation.

U.S. Census Bureau 2006a. Asian-owned Firms: 2002.

U.S. Census Bureau 2006b. Hispanic-owned Firms: 2002.

Williams, Patricia J. 1991. The Alchemy of Race and Rights. Boston: Harvard. 


\section{CHAPTER 5:}

\section{CONCLUSION AND DISCUSSION}

The study of ethnic culture and the integration of immigrant communities into mainstream American culture have made considerable advances in recent years. One of the largest advancements has been the recognition that ethnic individuals and communities are dynamic in the sense that traits, characteristics, and practices are by no means fixed, but more fluid in nature. Distinctions which have been historically used to categorize and label ethnic communities have been shown to weaken over time as they slowly infuse their receiving communities with their own cultural artifacts. This dissertation has shown that the realm of food is one of the most pivotal and present forms of cultural fusion. As a modern phenomenon, the Mexican restaurant industry has gone global. Mexican restaurants can be found on six continents and in over 150 countries around the world (Pilcher 2012).

In the United States, in particular, the growing Mexican immigrant community has begun to spread outside of the Southwestern Borderlands and into all regions of the country. Mexican immigrants alone, however, have not been the sole merchants of Mexican fare to the world. As demonstrated in this dissertation, the Mexican food industry is as much an American phenomenon as it is a Mexican one. American entrepreneurs such as Glen Bell, founder of Taco Bell, recognized the growing demand for cheap and hardy Mexican food and applied the McDonalds model to the production and distribution of Mexican food. As of 2015, Taco Bell now serves more than two billion customers per year from more than 6,500 restaurants worldwide, excluding 
Mexico where two different attempts to enter the Mexican fast food market with an “American" style menu featuring French fries failed.

Attempting to capitalize on this growing market for Mexican cuisine in the United States, many other American owned franchises have emerged. These include popular restaurants such as: Chipotle Mexican Grill, Qdoba Mexican Grill, Moe’s Southwest Grill, and Del Taco, who with Taco Bell represent the five largest Mexican fast food restaurant chains. Fast food restaurants such as these have been demonstrated to serve primarily customers outside the Mexican ethnic group. Ethnic Mexicans primarily frequently dine-in restaurants that are locally owned and operated. While a minority of Mexican restaurant chains does exist, such as El Maguey, On the Border, and Chevy's Fresh Mex, over $80 \%$ of Mexican restaurants are locally owned and operated by individual entrepreneurs.

As demonstrated in this dissertation the overwhelming majority of Mexican restaurant owners and staff members are recent Mexican immigrants. In many cases, these Mexican restaurants serve as pillars to the ethnic community and serve to funnel new Mexican immigrants to the community through developing a system of networks of individuals in search of secure employment. The emergence of a diverse market of Mexican food in the United States and the world has produced contesting definitions of authentic Mexican food.

The presentation and accomplishment of authenticity is undoubtedly a social construction. Scholars contend that the quest for authenticity is a modern development concerning the effects of globalization and pluralism on individual selfhood and social relationships (Trilling 1971; Handler 1986). Indeed, in this dissertation, the presentation 
of the "ethnic" self symbolized a form of self-expression which simultaneously served as a means of defining the boundary between "the collective self and the other" (OhnukiTierney 1993, 3). This, in turn, permitted ethnic Mexicans a frame through which they could understand their role in interactions. From this perspective, authenticity relies heavily on the definition of the situation as a "true" experience, person, or event. People, experiences, and events occur in a diverse range of social worlds and contexts. The findings of this project demonstrated that multiple variables contribute to both organizational and subjective claims to authenticity.

\section{The Rhythms of Mexican Restaurants}

In chapter two of this dissertation I explored the negotiated process of producing Mexican food. Many social actors and variables were demonstrated to have a significant bearing on both the production and interpretation of Mexican food as real, genuine, or authentic. From the restaurant management perspective, maintaining a consistent product to be served to restaurant patrons was of the upmost importance. Restaurant owners and managers consistently reported actively policing the cooking practices of cooks, who depending on what region of Mexico, level of culinary training, or passion for cooking they possessed chose to prepare the food as they saw fit. This led to daily variations in the same meals served to patrons with the same restaurant. From basic modifications such as including peas in Mexican rice to more significant modifications such as including cactus with fajita tacos, the type of authenticity served to patrons very much varied based on the cook scheduled.

In addition to organizational rhythms based in interactions within the kitchen, the authenticity of Mexican food in restaurants was also shaped by the availability of 
products needed to make traditional Mexican dishes. Fieldwork conducted for this dissertation found that in many cases, cooks in Mexican restaurants improvised their preparation of meals based on the resources available to them in the moment. On many occasions, servers were sent on frantic missions to buy canned tomatoes from the nearby grocery store in order to complete meals such as Mexican fideo (soup). On other occasions, pork was seasoned with beef seasoning and charred in order to produce the illusion of beef steak tacos.

Perhaps the most glaring example of improvisation in the kitchen was on a busy night when the restaurant ran out of salsa to serve alongside complimentary chips to restaurant patrons. In a frantic moment, the dishwasher hastily opened large cans of what he thought were tomatoes and added them to the vat of onions, cilantro, and seasonings. After blending the ingredients, the dishwasher dipped his chip into the salsa to test the flavor, instantly realizing his mistake. Unbeknownst to him he had blended tomato puree in lieu of diced tomatoes. The flavor was incredibly bitter and the consistency of the salsa was visibly off. Rather than make a new batch of salsa, a few more onions and spices were added to the pureed tomato based salsa and was served to clients for the rest of the night. Interestingly, not one single customer complained about the flavor or requested a new bottle the entire night.

The ability of the Anglo consumer, thus, was paradoxical in nature. On the one hand, consumers lacked any real knowledge of authentic Mexican food flavors or method of preparation. On the other hand, Anglo consumers drove the modifications to traditional Mexican food. As businesses, ethnic restaurants carefully managed their unique displays of taste and style within the bounds of a local environment's order of supply and demand. 
As such, the production of Mexican food was always done with the consumer in mind. Some Mexican restaurants hosted loyal customer nights where repeat customers who were on a friendly basis with restaurant management were invited to the closed restaurant for free food. In these closed sessions, cooks and managers asked their Anglo clients which dishes they liked best, what modifications they would like to see, and negotiated levels of spicy. In these interactions, the power to define what authentic food was not a pressing matter. What did matter were the types of Mexican foods which Anglo consumers would buy. As a matter of principle, the level of "authenticity" achievable in a restaurant always reflected the pallets of consumers who demonstrated their acceptance of a presentation of food with their patronage at a restaurant.

This dissertation reinforced the idea put forth by $\mathrm{Lu}$ and Fine (1995) which suggests that the "the success of ethnic food depends on the participation of its audience" (548). Since all of the ethnic restaurants in the Midwestern section of this study served clientele outside of the ethnic group, "authenticity" in taste and style emerged as a constant challenge for owners of Mexican restaurants attempting to accommodate personal cultural traditions with American expectations and pressures. In the end, the decision to make and serve authentic Mexican food with traditional ingredients and methods of preparation was dictated by the pursuit of profit. As businesses, Mexican restaurants needed to market food which consumers would buy. While some scholars (Gaytán 2008) have labeled this phenomenon as hybrid inauthenticity, this dissertation has found that the term "authentic imitation" may be better suited to describe the host of Mexican dishes served in Mexican restaurants which have the spirit of traditional Mexican food within them, but are in reality watered down meals prepared with 
ingredients , purchased at the local grocery store, sprinkled with a little extra chili powder, and packaged as an exotic experience to restaurant patrons who will never know the difference.

\section{Real Men in Context}

In chapter three, the gendered dimension of Mexican restaurant work was explored. It was found that kitchen work is almost entirely a male niche in the labor market. From cooks and servers to bartenders and busboys, Mexican restaurants are male dominated spaces. This dissertation contributed to the growing body of gender studies which critique the monolithic representation of Mexican masculinity as being rooted in machismo (Mirande 1997; Abalos 2002; Irwin 2003).

Before such studies of the gendered cultural landscape in Mexico, machismo was often used to frame most, if not all, interactions between genders. As such, Mexican masculinity has long been defined as the struggle for power between men and the domination of women (Chant and Craske 2003; Ramirez 2011). In many ways, machismo has been shown to not only be an exercise of power and authority over women, but also as a case of men oppressing other men who are not deemed to possess socially acceptable masculinity.

While this portrayal of Mexican masculinity is indeed valid for many historical and contemporary communities, it does account for the range of definitions of masculinity in practice. Yes, the kitchens of restaurants in this study were rife with the sexual objectification of women. Restaurant staff frequently exchanged stories of sexual conquest, fantasies about restaurant patrons, and otherwise flaunted their sexuality to anyone in their presence. They were also sites where manhood was measured in very 
stereotypical ways. The type of car a worker had granted an immense about of social capital and served to boost one's masculinity. Additionally, the dominant cultural narrative of men as providers holds strong in the immigrant communities in this study. The more remittances a worker could send back home to family and communities, the more respect and social capital accrued with their fellows in the restaurant.

This dissertation also contributes to the literature on the mechanisms of producing new and evolving forms of gender roles and ideologies. In particular, the findings of this project support the argument that identities are shaped by social context, and are thus fluid. In particular, an individual's relationship to authority in a social hierarchy, geography, and exposure to mainstream U.S. influences have all been found to structure individual agency and identity formation.(Baca Zinn 1982; Ramirez 2011). In the case of this research, recent Mexican immigrants navigated their new social context, and constructed new norms, values, and cultural frameworks through which they defined themselves and others.

Indeed, as Gutman (1996) points out, many Mexican men see themselves $n i$ macho ni mandolin (neither macho nor apron wearing). While it may be that many Mexican immigrant men in the United States embrace "ranchero masculinity," as a result of their socialization, this research has shown that gender, and more specifically, masculinity, is a fluid social construction which, on a pragmatic level, adapts to social environments and influences. As a male dominated space with almost no female presence, the men working in restaurants adapted to their new social context. They created a hybrid form of masculinity. In this new hybrid form of masculinity, it was socially acceptable to dance with other men, to demonstrate sexual intimacy with other 
men, and to generally engage in homoerotic behavior with no social sanction, all the while maintaining a consistent objectification of women.

Many men acknowledged the lack of women both in the restaurant staff and in their daily lives. Almost none had any significant others at any point of the research process. The more time I spent interacting with staff, the more I realized how difficult this was for the immigrant men. Many of the restaurant workers resorted to highly unethical methods for attracting women. Some provided female patrons of the restaurant with drinks "onthe-house" in the hopes of reducing their inhibitions. Others used credit card receipts to identify the names of female patrons in order to seek them out on social media sites. Over the two years of fieldwork for this project, not one such effort resulted in any relationship with a woman. As one might imagine, sexual tensions ran high in these restaurant kitchens. In March of 2015 as this research project drew to a close, a heinous event occurred in one of the kitchens fieldwork took place.

While the exact motives of the attack are unknown, one evening a server continuously provided free alcoholic drinks to a frequent customer. Before settling her tab and leaving for the night, she used to restaurant restroom. Anticipating her trip to the restroom, the server waited in the women's restroom for her to enter. When she did, he sexually assaulted her. Without any sort of warning or provocation, many restaurant workers and community members wonder how such an act could occur on a typical Wednesday evening in downtown Columbia, MO. As this dissertation research suggests, Mexican restaurant kitchens are male dominated spaces where masculinity is fluidly constructed. Restaurant workers sought to achieve traditional "ranchero masculinity," but 
influenced by the social structures around them, they formed a hybrid version of traditional masculinity.

\section{Perceptions and Realities of Discrimination in Mexican Restaurants}

Chapter four was an exploration of the modern ethnic restaurant industry. Paying special attention to the Mexican restaurant industry, this dissertation investigated the paradox that exists between the growing demand for ethnic cuisine, and growing antiimmigrant sentiments. As discussed in chapter four, the economic recession of the first decade of the 21 st century led to a decrease in stability and profitability for restaurateurs. Heralded for its greater convenience and affordability, the Mexican food industry, both in its fast food variety as well as local dine-in restaurant form have increased in both the profits and numbers in both the United States as well as around the globe. The degree to which Asian and Latin American communities and foods are experiencing integration into mainstream American culture is highly contested. Unlike previous European immigrant groups such as Irish, Italians, and Germans, in many cases Latin American and Asian communities remain culturally and institutionally unassimilated in the United States. (Massey and Sanchez 2006; Jimenez 2009; Boland 2012).

Despite these stalled assimilation trajectories for immigrant communities, Mexican food are more popular than ever in the United States. For instance, Mexican restaurants are now the 3rd most popular menu type in the USA, representing 8 percent of the total national restaurant landscape (CHD 2014). While Mexican food has long been popular in the Southwestern Borderlands, it is now in high demand in other regions of the country as well, including the Midwest and Southeast. As Boland (2012) explains, Mexican food, including and certainly not limited to, nachos, tacos, burritos, chips and salsa, fajitas, 
quesadillas, and black beans are today as American as hot dogs and relish. The pattern of rapid expansion of Mexican food options and availability is not unique to the United States. In Europe, Mexican food is now the leading ethnic food sold in each country (except the United Kingdom where Indian food dominates), and for many consumers, Mexican food is considered "American food," which may be a manifestation of a lack of a heavy Mexican immigrant population in Europe.

In chapter four, the role of institutional actors, in this case a public health inspector, in contributing to the labeling and marginalization of ethnic communities and restaurants was also investigated. Using a critical race theory lens, the findings of this study reinforced existing critiques of modern color-blind ideology. In particular, dominant cultural narratives of ethnic restaurants being dangerous, dirty, or beneath the standards of American restaurants were found to contribute to a climate of labeling ethnic restaurants and communities in Anglo dominated spaces as different. As demonstrated in chapter four, this othering process leads to significant issues for ethnic restaurateurs who must deal with prejudice in public discourse and health inspections. Restaurant owners and staff members were quick to point out feelings of discrimination from members of the surrounding community as well as from institutional level actors such as public health inspectors.

Upon analysis of a random sample of ten Missouri counties, it was found that public health inspectors are more likely to report health code violations against ethnic restaurants than non-ethnic restaurants. As such, non-ethnic restaurants in this study on average had higher health inspection scores and fewer public shaming. Many scholars point to poor training practices, insufficient knowledge or desire to perform safe food 
handling, and language barriers as explanations of health code violations. While not to dismiss the severity or risk associated with improperly handling or preparing food, this paper suggests that institutional level discrimination directly relates to more health code violations and economic ramifications in ethnic restaurants.

In many ways, the experiences of owners and staff of ethnic restaurants were found to represent ongoing tensions between racial and ethnic groups in the United States. The importance of power, both on an individual and community level functioned to establish the norms and values of the community. In the case of Mexican restaurant owners and staff in the Southwestern Borderlands, power was with within the ethnic community. As such, restaurant management consistently reported a sense of authority in the community, control over the operations of the restaurant, and as pillars in the community. Additionally, Borderlands restaurateurs expressed opinions of widespread marginalization of non-ethnic entrepreneurs seeking to establish a Mexican restaurant in their community.

In a vastly different social environment in the Southwestern Borderlands, Mexican restaurant owners and staff actively policed the boundaries of acceptable Mexican food. While the authenticity of the specific meals were never directly addressed, the assumption and prejudice which dictated that only ethnic Mexicans could operate a successful Mexican restaurant served to marginalize outsiders and maintained control of the Mexican restaurant market within the community itself. Outside the Southwestern Borderlands in the Midwestern United States, the power of the ethnic community was almost completely the opposite. Whereas Mexican communities were well established 
and highly proportional to the entire population, Midwestern ethnic communities, both in the case of Mexican and Asian, were significantly in the minority.

\section{Significance of Study}

This ethnographic study of the Mexican restaurant industry was important and needed for several reasons. First, this study was the first of its kind in the Midwestern United States. Filling in this tremendous gap in the literature on the production and presentation of authentic Mexican food and communities, this research brought to light the world of Mexican restaurant work. Up to this point in time, the available literature has almost exclusively focused on traditional Mexican settlement communities in major urban environments and along the East and West coasts of the United States. Of this existing scholarship, the vast majority of research conducted has focused on the economic reasons why a restaurant may present a knowingly inauthentic presentation of food in order to satisfy non-ethnic clientele. By design, my approach produced a more in depth and critical analysis of the behaviors and ideologies of social actors within the restaurant community who are actively involving in policing the boundaries of acceptable foods and behaviors in their communities.

The contribution of "organizational rhythms" presents a new take on the daily negotiation of restaurant workers who work to present a consistent and socially acceptable form of subjective and organizational authenticity. Additionally, the study of men performing traditionally women's work offered the opportunity to explore new and ever evolving constructions of masculinity. Building on existing research of modern masculinity, this research emphasized the negotiation of homosocial activity as part of a structurally influenced form of masculinity. Finally, the application of critical race theory 
to the realm of restaurants offered a unique look into a mundane and unchallenged realm of discrimination in everyday life. By focusing on the often hidden world of public health inspections, this research has the potential to inspire future studies of the hidden mechanisms of discrimination many racial and ethnic communities continue to experience in their work and private lives.

\section{Future Research}

There are several possibilities for future research to build on this research project. First, scholars could explore the influence of age on employment in Mexican restaurants. As a economic niche dominated by young men, fieldwork for this project included interviews and observations of only two restaurant servers over the age of 35 . What happens to the young men who work in restaurants as they age? Do they transition to a different economic niche? Do they return home to families and communities? A clue to the answers to these questions might be found in fieldwork for this project. Older workers were repeatedly mocked and teased by younger workers. They were often left out of conversations and granted less respect. Could it be that immigrant men age out of socially acceptable jobs in restaurants?

Second, researchers could examine the role of Mexican restaurants as pillars of community values and stability. On several occasions in this research, restaurants were closed during normal work hours for birthday parties, religious celebrations, and community gatherings. During these times, only ethnic Mexicans by invitation were allowed to enter the restaurant. Future research could explore how these practices influence the norms and values of the community. In small immigrant communities, how powerful are restaurant owners is directing the social trajectory of the community? 
Finally, scholars could examine the role of sports, and more specifically, soccer in the maintenance of ethnic identities in immigrant communities. In this research project, a local soccer league sponsored by local Mexican restaurants facilitated competition between restaurant staffs. Future research could investigate how this non-economic competition contributes to or detracts from a climate of competition between restaurants. Additionally, future research could investigate the degree to which success on the soccer field for a restaurant correlates to claims and perceptions of authenticity in the local Mexican restaurant community. 


\section{REFERENCES}

Abramson, Corey E., Modlewski, D. 2010. "Caged Morality: Moral Worlds, Subculture, and Stratification Among Middle-Class Cage Fighters." Qualitative Sociology, 34, 143-175.

Apostolidis, Paul. 2005. Hegemony and Hamburger: Migration Narratives and Democratic Unionism among Mexican Meatpackers in the US West. Political Research Quarterly 58: 647-670.

Arbelaez, Maria. 2002. "Good Friday in Omaha, Nebraska: A Mexican Celebration." Great Plains Research 12(1) 13-26.

Arreola, Daniel (ed.) 2004. Hispanic Spaces, Latino Places: A Geography of Regional and Cultural Diversity. Austin: University of Texas Press.

Bourgois, Philippe, and Jeff Schonberg. 2007. "Intimate Apartheid: Ethnic Dimensions of Habitus Among Homeless Heroin Injectors.” Ethnography 8, 1: 7-31.

Cadge, Wendy, and Elaine Howard Ecklund. 2006 "Religious Service Attendance among Immigrants: Evidence from the New Immigrant Survey-Pilot," American Behavioral Scientist, 49(11): 1-22.

Cornell, Stephen and Douglas Hartmann. 1998. Ethnicity and Race: Making Identities In a Changing World. Thousand Oaks, CA: Pine Forge Press.

Crenshaw, Kimberle W. 1991. "Mapping the Margins: Intersectionality, Identity Politics, and Violence against Women of Color." Stanford Law Review, 43, 6: $1241-1299$.

Du Bois, W. E. Burghardt. 1984. Dusk of Dawn: An Essay Toward an Autobiography of a Race Concept. New Brunswick: Transaction Publishers.

Du Bois, W.E. Burghardt. 1899. The Philadelphia Negro. Philadelphia: University of Pennsylvania Press.

Durkheim, Emile. 1912. Elementary Forms of the Religious Life. New York: Free Press.

Gerth, H. H. and C. Wright Mills, ed. 1946. From Max Weber: Essays in Sociology. New York: Oxford University Press.

Gubrium, Jaber F. and James A. Holstein. 1999. The Self We Live By: Narrative Identity in a Postmodern World. London: Oxford University Press. 
Hall, Stuart. 1996. "The Problem of Ideology: Marxism Without Guarantees." in Stuart Hall: Critical Dialogues in Cultural Studies, edited by D. Morley and K-H. Chen. Routledge.

Harbison, Sarah F. 1981. Family Structure and Family Strategy in Migration Decision Making. New York: Center for Cultural and Technical Interchange between East and West, Inc.

Lamont, Michele. 2000. The Dignity of Working Men. Harvard.

Lockhart, Lettie., and Danis, Fran, S. 2010. Domestic Violence: Intersectionality and Culturally Competent Practice. New York: Columbia University Press.

LaFaye, Jacques. 1976. Quetzacoatl and Guadalupe: The Formation of Mexican National Consciousness 1531-1813. Chicago: University of Chicago Press.

Menjívar, Cecilia. 1999. Religious Institutions and Transnationalism: A Case Study of Catholic and Evangelical Salvadoran Immigrants. International Journal of Politics, Culture and Society, 12 (4): 589-612.

Min, Pyong Gap. 2010. Preserving Ethnicity Through Religion in America: Korean Protestants and Indian Hindus Across Generations. New York: New York University Press.

Pharr, Suzanne. 1997. Homophobia: A Weapon of Sexism. Berkely: Chardon Press.

Ronai, C.R. 1992. "Seperating Aging From Old Age: The Aging Table Dancer." Journal of Aging Studies, 6,4.

Said, Edward. 1979. Orientalism. New York Vintage Books.

Sanders, Jimy M. 2002. "Ethnic Boundaries and Identity in Plural Societies." Annual Review of Sociology, 28:327-57.

Steedman, Carolyn. 1986. Landscape for a Good Woman. Rutgers.

Steinberg, Stephen. 1981. The Ethnic Myth: Race, Ethnicity and Class in America. Boston, MA: Beacon Press.

Stoler, Laura A. 2002. Carnal Knowledge and Imperial Power. California.

Telles, Edward and Vilma Ortiz. 2009. Generations of Exclusion: Mexican Americans, Assimilation, and Race. New York: Russell Sage Foundation.

Waters, Mary. 1990. Ethnic Options: Choosing Identities in America. Berkeley, CA: University of California Press. 
Yang, Fenggang and Helen Rose Ebaugh. 2001. Transformations in New Immigrant

Religions and Their Global Implications. American Sociological Review 66:269- 288. 


\title{
APPENDIX A: INTERVIEW PROTOCOL
}

\author{
Interview Protocol
}

Date

Location

Racial/Ethnic

Group

Pseudonym

\section{Introduction}

- Introduce yourself

- Discuss purpose of study

- Provide informed consent

- Provide structure of interview (audio-recording, taking notes, and use of pseudonym)

- Ask if they have any questions

- Get verbal informed consent

- Test audio-recording equipment

- Smile and make the participant feel comfortable

\section{Theme 1: Ethnic Background}

1. How do you define your ethnic background?

a. What about the ethnic background of your parents?

2. Have you always held this idea of your ethnic status?

a. Were you encouraged to present yourself in a certain way?

b. Were you discouraged to present yourself in a certain way?

3. Tell me about ___ ethnic group.

a. What makes them ethnically distinguishable?

4. Can you describe an experience when you felt most ethnic?
a. Party?
b. Special event?

5. Can you describe an experience when you felt least ethnic?
a. School?
b. Dating?

\section{Theme 2: Ethnic Credentials}

1. How many languages do you speak?
a. What is your preferred language?
b. When/how did you learn the language?
c. Which language do you speak most often? 

d. At work?
e. With friends?
f. With family?

2. What types of foods do you like to eat?
a. Do you cook for yourself?
b. Do you go out to a lot of restaurants?
i. What kind?
ii. How do you pick one restaurant over a different one?

3. What do you do in your free time?
a. Do you spend a lot of time with co-ethnics?
b. Do you try to spend time with co-ethnics?

\section{Theme 3: Authenticity in Everyday Life}

4. What does authentic mean to you?

5. Think about your ethnic group.
a. Describe to me what an authentic is like?
b. Can you tell me what an inauthentic is like?
c. Where did you think you got these ideas?

6. Has anyone ever challenged your authenticity as a $?$
a. Why?
b. What happened?
c. How did you feel?
d. How did you respond?
e. Does this instance still bother you?

7. Have you ever challenged anyone's authenticity as a $?$
a. Why?
b. What happened?
c. How did you feel?
d. How did others respond?
e. Does this instance still bother you?

8. How easy is it to be a $?$

a. Do you have a lot of pressures to be a certain way?

b. Where do the pressures come from?

9. What types of things do you do in your daily life that make you a $?$
a. Are these conscious decisions?
b. Do you like to do these things?

10. How do you maintain an authentic ethnic identity? 

a. Religion
b. Family
c. Media consumption
d. Social networks

11. Have you ever been to $?$
a. What was it like?
b. Did you feel like you fit in?
c. Did you feel like you stood out?
d. How was it different from being in the USA?

12. How does it feel to be around co-ethnics?

a. Do you change the way you act?

b. Do you feel like you belong?

\section{Theme 4: Authenticity in Restaurants}

1. How would you describe your restaurant as authentic?

2. Do you struggle with presenting an authentic food or restaurant experience? If so, why?

3. Who cooks at your restaurant?

a. Are they professionally trained?

b. Are there disagreements about how the food should be prepared?

4. What kinds of people eat at your restaurant?
a. Mexicans
b. Whites

6. Who works at your restaurant?

7. Where do you get your food products from?

a. Does this affect the level of authenticity you can present?

b. Where do you think other Mexican restaurants get their food?

8. Do you ever feel discriminated against by health inspectors?

\section{Concluding Statements}

- Is there anything else you would like to add or share about this topic that you feel is important for me to know?

- Thank them for their participation

- Pay them

- Ask if they would like a copy of the final results (email:

- Record any thoughts, feelings, observations, and reactions about the interview. 


\title{
APPENDIX B: INFORMED CONSENT FORM
}

\author{
The Social Organization of Authenticity in Mexican Restaurants
}

\section{Dear Participant:}

You are invited to participate in a research study that will attempt to understand the construction of authenticity in Mexican communities and restaurants. You can decide not to participate. The following information is provided in order for you to make an informed decision whether or not you would like to participate. If you have any questions, please do not hesitate to ask. You are eligible to participate in this study because you have reported to be an owner, worker, or patron of a Mexican restaurant, or an individual who identifies as Latino/a.

Project: The Social Organization of Authenticity in Mexican Restaurants

Purpose of the Project: This study will investigate the organizational and subjective claims to authenticity which are made in Mexican communities and restaurants. More specifically, this project seeks to understand how food signifies culture, tradition, and important ideas about authenticity.

Procedures: You will be asked to participate in an interview with the primary investigator. This interview will last approximately one hour. The interview will be audio-recorded and will take place at a location at your convenience. During this interview, you will be asked a series of questions. These questions are designed to allow you to share your personal experiences as a member of the Columbia, MO Mexican restaurant community.

Risks and/or Discomforts: There are no known risks or discomforts associated with this research.

Benefits: The information gained from this study may help us to better understand the social organization of authenticity in Mexican restaurants in the Midwest. This understanding may, in turn, influence community, state, and national policies regarding restaurants.

Confidentiality: During the interview, you will be asked to provide a pseudonym (false name) to insure that your identity is kept confidential. The audio-recording will be assigned the pseudonym that you pick during the interview. Audio recordings will be used only to transcribe interviews. Once the interview is transcribed, the audio tapes and interview transcripts will be kept in a locked cabinet at the University of Missouri in the office of the principal investigator. The information obtained during this study may be published in academic journals or presented at academic meetings, but there will be no possible way to link information to people or places.

Compensation: You will be not be compensated for participating in this study . 
Opportunity to Ask Questions: You may ask questions concerning this research and have those questions answered before agreeing to participate or during the study. Or, you may call the principal investigator, Stephen Christ, (660) 864-1998 or email src257@mail.missouri.edu. If you have any questions about your rights as a research participant that have not been answered by the investigator or to report concerns about this study, you may contact the University of Missouri Institutional Review Board, telephone (573) 882-9585.

Freedom to Withdraw: You are free to decide not to enroll in this study, or to withdraw at any time without adversely affecting your relationship with the investigator or the University of Missouri. Your decision will not result in any loss of benefits which you are otherwise entitled.

Consent: If you wish to participate in this study, you will be interviewed. You are voluntary making a decision whether or not to participate in this research study. Your verbal consent certifies that you have decided to participate having read and understood the information presented. You will be given a copy of this consent form to keep.

Do you wish to participate?

Yes, in my judgment, I am voluntary and knowingly giving informed consent and posses the legal capacity to consent to participate in this research study.

OR

No, I do not want to participate in this study. 


\section{VITA}

Stephen is married to his very best friend, Marie. Together, Marie, his terribly feisty cat, Oliver, and mischievous dog, Toby keep Stephen grounded and enthusiastic about research and teaching. Growing up in the Southwestern Borderlands, Stephen has long been interested in immigration, race/ethnicity, culture, and human rights. He earned his B.A. in Spanish at the University of Central Missouri, a Graduate Certificate in Women's and Gender Studies at the University of Central Missouri, and a M.A. in Sociology (also from UCM). After graduating with his PhD in Sociology from the University of Missouri, Stephen plans to continue a life dedicated to studying Mexican Americans and advocating for social justice. In the fall of 2015, Stephen will begin his tenure as Assistant Professor of Sociology at Truman State University. In his spare time, Stephen is competitive in sports. He is an avid tennis player, scratch golfer, and bowling league champion. If Stephen does not find success in academia, he intends to pursue a career in stand-up comedy. Stephen teaches courses on immigration, criminology, religion, and research methods. 